\title{
Corporate boards, interorganizational ties and profitability: the case of Japan
}

\author{
Matthias Raddant ${ }^{1,2,3}$ (1) $\cdot$ Hiroshi Takahashi ${ }^{3}$ (]) \\ Received: 29 August 2020 / Accepted: 17 April 2021 / Published online: 20 May 2021 \\ (c) The Author(s) 2021
}

\begin{abstract}
We analyze the ties between 4000 Japanese corporations in the time period from 2004 until 2013. We combine data about the board composition with ownership relationships and indicators of corporate profitability. The board network exhibits some clustering, which can partly be explained by ownership relations, and a tendency to form ties to other corporations from the same sector. Connectivity in the board network (corporate board interlocks) and ownership network (shareholdings) does have an influence profitability. Firms that are linked to peers with above average profitability are more profitable than firms in other relationships. Hence, network effects partly explain why board interlocks and ownership ties are not always beneficial.
\end{abstract}

Keywords Corporate board interlock · Firm performance · Firm networks · Executive survival

JEL Classification L25 - G32 · M12 · C55

\section{Introduction}

We study the interorganizational networks of Japanese corporates from 2004 until 2013. We focus on corporate board interlocks and ownership ties. We investigate the network structure and we analyze if and under which conditions ties in either network are related to firm profitability.

An increasing amount of scholars in the fields of business and economics have recently put more emphasis on describing economic performance as the outcome of

Matthias Raddant

mraddant@gmail.com

1 Department of Economics, Kiel University, Olshausenstraße 40, 24118 Kiel, Germany

2 Kiel Institute for the World Economy, Kiellinie 66, 24105 Kiel, Germany

3 Graduate School of Business Administration, Keio University, Yokohama, Kanagawa 223-8526, Japan 
networked activity. This paradigm has been applied from a macroeconomic perspective, for example by Acemoglu et al. (2012), but also on the level of firms and sectors (Herskovic 2018; Ahern 2013; Aobdia et al. 2014) in the networks of production and trade. The interorganizational networks that are at the core of this approach have been analyzed by researchers from different fields, such as sociology, management and corporate finance, interdisciplinary physics, computer and network science. This has led to a literature that is partly segregated, despite dealing with closely related topics. This research is therefore also a step in connecting the different findings and viewpoints from these disciplines.

Board interlocks emerge when directors serve on the boards of more than one company. Most importantly, board interlocks and other interorganizational networks have been analyzed as influencing factor on firm profitability, strategy, managerial practice and corporate governance (see, e.g., Hermalin and Weisbach 2003; Mizruchi 1996; Gulati and Gargiulo 1999; Kramarz and Thesmar 1992). Cai et al. (2014) found significant interaction effects between connected corporate boards with respect to disclosure policies, Bizjak et al. (2009) found similar effects with respect to employee stock options, Chiu et al. (2013) found such effects with respect to earnings management.

In the sociological literature, firm connectivity is mostly regarded as necessary to provide opportunities for firms to develop (see, e.g., Uzzi 1996). The efficient creation of ties with other companies is thus expected to lead to an increase in corporate valuation. Yet, many studies also stress that ties should be carefully managed, since they can have positive as well as negative effects on firm performance (Barroso-Castro et al. 2016; Sullivan and Tang 2013).

Management science has analyzed board interlocks by applying agency theory, which tends to stress negative effects from board interlocks. Approaches that model resource considerations on the other hand tend to stress benefits (see Jensen and Meckling 1976; Pfeffer and Salancik 2003). The empirical results on the effects of board interlocks are similarly divided (see also Lamb and Roundy 2016). Positive effects on performance are found for example by Horton et al. (2012), while Devos et al. (2009) find negative ones. Zona et al. (2018) therefore try to combine different perspectives on board interlocks and find that effects likely depend on a firm's relative strengths and weaknesses. Our study contributes to this debate by looking at interaction effects between connected firms. Many of the above-mentioned studies analyze samples of limited size or focus on specific aspects of firm behavior. Our approach is comparably general and is applied to a large sample of firms. Although our approach differs from Zona et al. (2018), we find similar conditional effects of board interlocks and also of ownership ties. Our results thus strengthen the view that effects from interorganizational ties depend on firm characteristics and its position in the network.

A different facet of this debate, mostly in corporate finance, is the composition of the board. There is no consensus on the question if the appointment of outside board members is of any benefit to ensure good governance and accurate reporting (see the survey by Petra 2005). While an independent board is generally regarded as best practice, a link to performance can mostly not be established (Dalton and Dalton 2011). Nevertheless, we observe an increasing number of outside board members in Japan. While there is no evidence that this leads to significant differences in firm performance (Miwa and Ramseyer 2005), there is some evidence that foreign ownership has an 
effect on firm valuation (Mian and Nagata 2015). We find support for this claim, since we observe a growing number of outside board members at firms with foreign shareholders.

Corporate interlocks are also an interesting phenomenon for social networks science, since the networks of directors with multiple mandates are (partly by construction) very dense and show high degrees of clustering, even though the average connectivity is very low (Conyon and Muldoon 2006; Davis et al. 2003; Battiston and Catanzaro 2004). Less research has focused on the dynamics of corporate interlocks, but it seems clear that some amplification mechanisms are in place that foster multiple mandates at highly capitalized firms and that imply replacement of very central directors with alike peers when board members retire or leave the company (Milaković et al. 2010; Bellenzier and Grassi 2014; Mariolis and Jones 1982; Raddant et al. 2017). In our analysis of the dynamic properties of corporate ties, we find similarly persistent structures in the Japanese case, and we also observe that firm growth is closely related to firm connectivity.

A topic that is specific for the Japanese economy are the fading effects of the so-called keiretsu (Lincoln and Shimotani 2001). This term describes six historic conglomerates of corporations that have dominated the Japanese economic landscape after the second World War. Studies found that today only very few traces of their former structure can be found, even though the names of the original concerns persist. Yet, risk sharing mechanisms within ownership structures have been identified as an influence on firm performance (see Schaede 1995; Lincoln and Gerlach 2004; Nakano and Nguyen 2012; Lincoln et al. 1992). Our analysis of the different relationships in the board and ownership network can therefore also be seen as continuation of these studies.

In the following, we will first review the dataset and the methods that we have applied in Sect. 2. After this, we will discuss the board members and their ties in Sect. 3. Section 4 deals with the structure of the board network. In Sect. 5, we discuss board composition and the role of outside board members. At last, we will analyze dependencies between firm connectivity and profitability.

\section{Materials and methods}

\subsection{Company data and network generation}

The Japanese system of corporate boards used to be a very special one at least until the 1990s. Boards used to be large and had limited intend to care about international governance standards or even shareholder value. Really important decisions were taken within smaller groups of senior board members anyhow. The crisis of the 1990s lead to some change and influence from the US system. Following Sony, boards mostly shrank to a size of about 10 corporate executive officers plus 2 to 3 externals, including the auditor. An alternative system is the company with committees. In this system, additional to the board of directors, three committees would handle audit, nomination and remuneration duties (Buchanan and Deakin 2009). Hence, in our analysis, we look in the very large majority at cases where the board of directors consists of 6 to 15 
corporate executive officers, 1-2 auditors and possibly 1 or 2 outside board members. Only few mainly very large corporations report up to 35 total board members.

For our analysis, we have collected data of all publicly listed companies in Japan. Most of these are listed at the Tokyo Stock Exchange (TSE). This means that our sample includes all the roughly 1700 firms of the so-called first section together with a similar amount of slightly smaller firms, totaling close to 4000 firms per year. We combine the data on the composition of corporate boards available from Toyo Keizai with financial data obtained from Nikkei Needs and Thompson Reuters Datastream. In particular, we use the information on market value, income, total assets, the business sector, largest shareholders and shareholder composition. This data is not available for the entirety of listed firms; hence, some parts of our analysis will be carried out using sub-samples of the data.

The information on the composition of the board is updated annually in the middle of the year. Besides the names of the board members, we have obtained information on the age, gender and role of the board member. The naming and numerical identifiers of board members are unanimous within each year, but not necessarily throughout the years. Hence, we have developed an algorithm to trace the destinies of board members over time based on parts of their names, date of birth and affiliations and have created our own identifier, which is unanimous for the entire sample period. ${ }^{1}$ The financial data of the firms is matched using the same yearly frequency.

The basics of the treatment of the board composition data are simple. For each year, we observe a set of board members and a set of firms. Board members serve on the boards of one or more firms. This creates relationships (incidences) between the set of board members and the set of firms and resemble a bipartite graph. Incidences can be described by positive entries in a matrix $I$, where the dimensions of $I$ are given by the number of firms and the number of board members within a year.

From the incidence matrix $I$, we can obtain an undirected network that describes the links between the boards of these firms by projecting $I^{\prime} I=A_{B} . A_{B}$ is a square matrix with as many rows and columns as we have firms in our sample. A positive entry $A_{i j}$ describes a connection between the firms $i$ and $j$ that is given by at least one shared board members. In the following, we will refer to this network as the board network. $^{2}$

\subsection{The board network}

The network that we look at naturally shows some churning over time, caused by entry and exit of firms as well as retirement and replacement of board members. Nevertheless, the basic statistics provided in Table 1 shows that the number of firms varies steadily between 3532 and 3943. (The number of distinct firm for all years is

\footnotetext{
1 We have confirmed the validity of this algorithm by manual checks. The only known limitation of this method is that we may lose traces of board members who exit the dataset and re-appear at a later year at a different company. We are however confident that this problem applies only to a very limited number of board members who did not play a decisive role in the board member network anyhow.

2 A different interpretation of the data would be the network derived by the projection $A_{D}=I I^{\prime}$. This adjacency matrix would describe relationships of board members who know each other from serving on at least one board together. This network is however not part of the following analysis.
} 


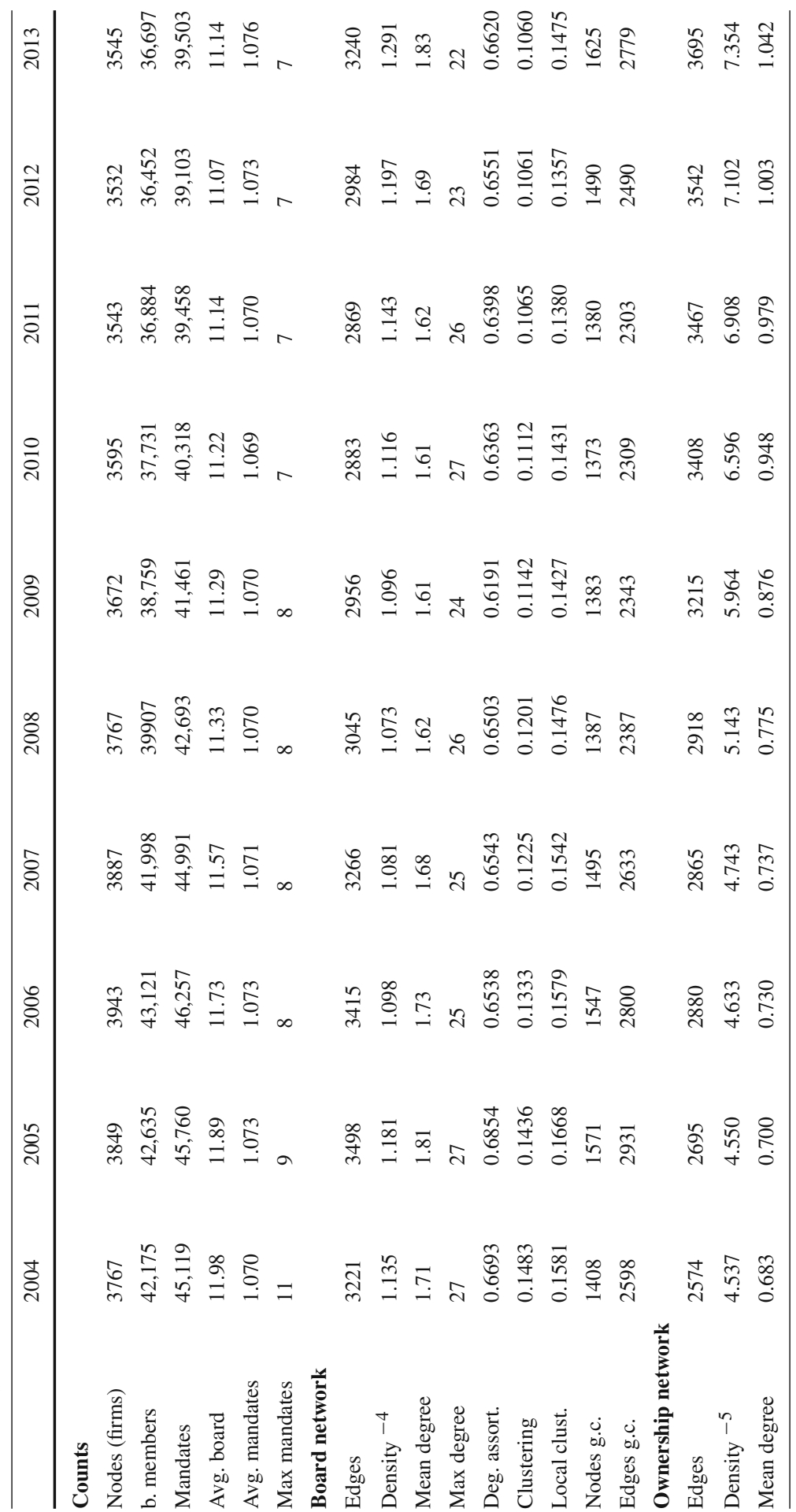




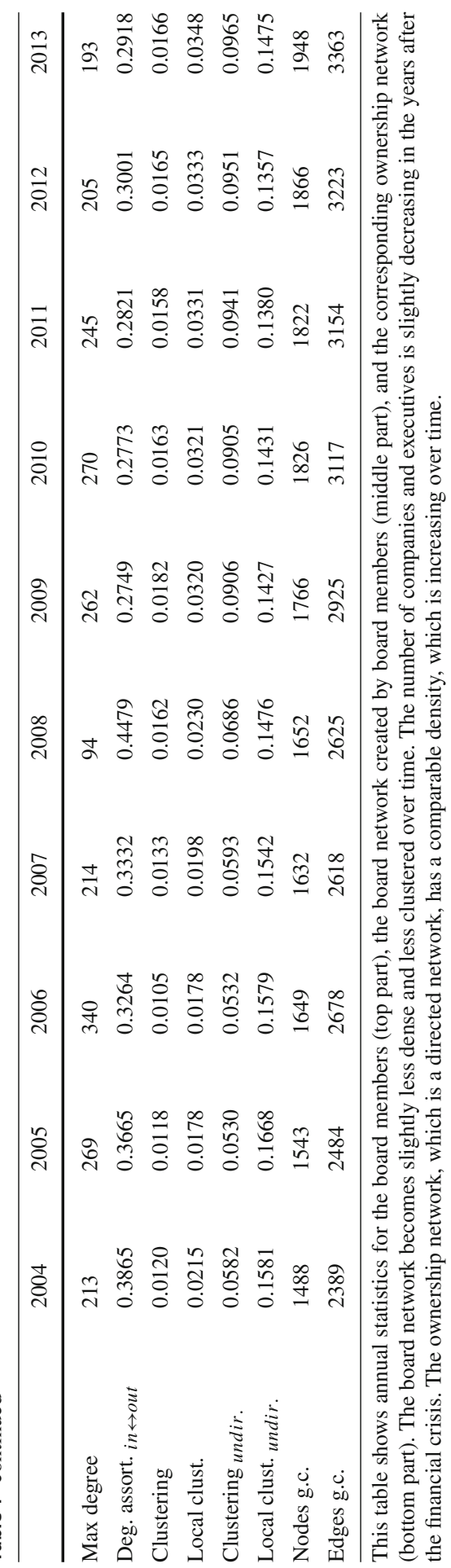




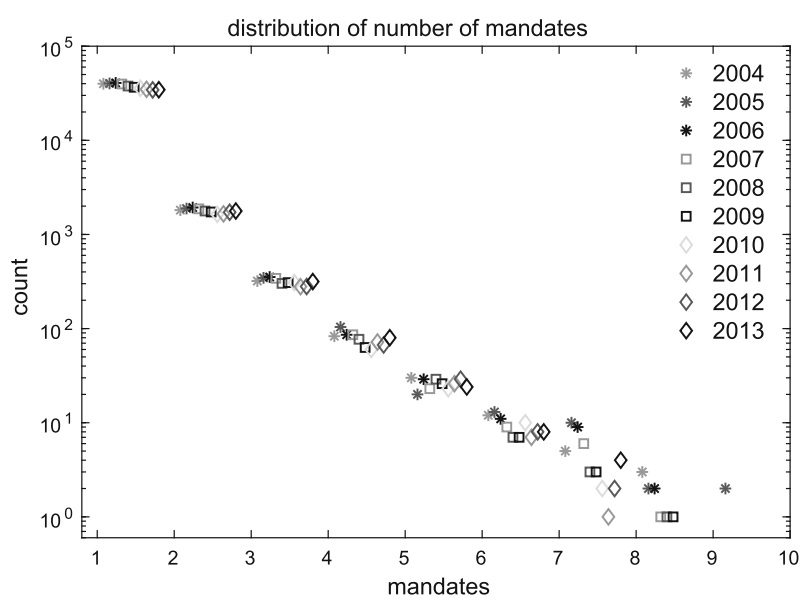

Fig. 1 Mandates statistics. We print the number of mandates with an offset and use a log-scale for the count. The tail of the distribution shows similarity to a power-law. The highest numbers of mandates are only observed until 2009

4505.) In the same time, the average number of board members is slightly declining from almost 12 in 2004 to 11.1 in 2013. The number of board members we observe per year lies around 40,000 (distinct: 95,192).

We can measure the survival of firms by looking at the stock identifier codes. We observe that the unconditional survival probability of the firms in our data set is very stable and lies around 96\% (see also Table 7 in the "Appendix"). Slightly lower values are only observed around 2007, which is in line with the weak GDP growth at that time. The same exercise can be done for the board members. The survival rates for them are also rather stable and vary around $83 \%$. Slightly lower figures are observed around 2007-2008 and slightly higher values are observed toward the end of the sample period (see also Table 8 in the "Appendix").

The disparity between the average number of mandates and its maximum demands a short look at the distribution of the number of mandates. Figure 1 shows that this distribution is heavy-tailed. While around 40,000 board members have one mandate, only around 200 have three mandates, and only a handful of board members find themselves with eight or more. The degree distributions of the board networks are roughly in line with a power-law (see the left panel in Fig. 2). The estimated powerlaw exponents range from 3.2 to 3.6 , which should be interpreted with caution given the low range of the degrees.

The middle part of Table 1 shows some statistics for the unweighted board network. The mean degree and the very low density reveal that in fact many firms do not share any board member. The correlation between a node's degree and the average neighbor's degree (i.e., the degree assortativity) is positive. The networks show transitivity. We find positive local clustering and a significantly positive (global) clustering coefficient (compared to a random network with identical degree sequence). To some extend, these effects result from ties between firm conglomerates, which can be confirmed by applying community detection algorithms to this network. We are not interested 

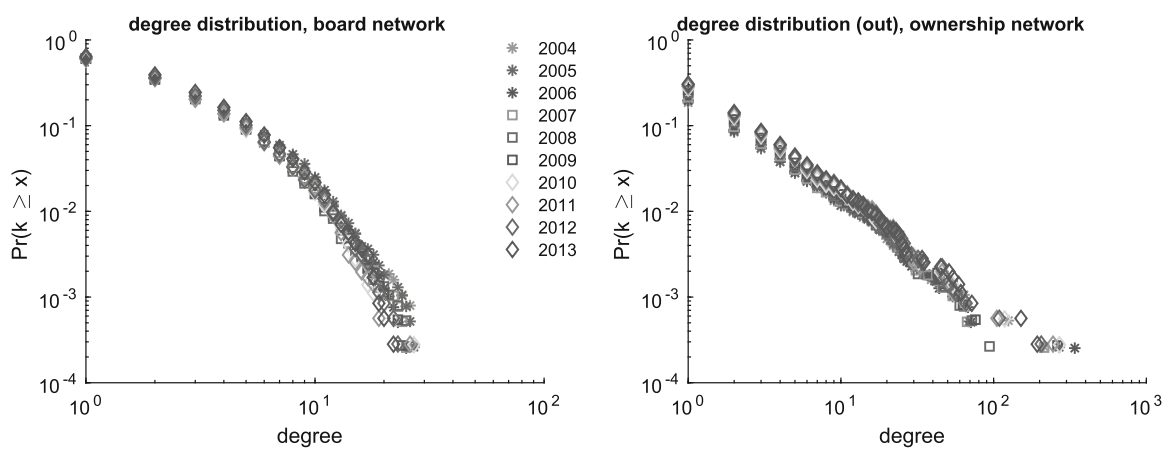

Fig. 2 Degree distributions (complementary cdfs). The degree distributions of the board network (left) are skewed and shows similarity to a power-law, yet the range for the degree is rather low. The degree distribution of the ownership network (right) shows a more typical power-law behavior

in the details of community structure in this study, yet one possible visualization of communities is provided in Fig. 10 in the "Appendix".

While the board network shows some similarities with a social network, we also have to stress the differences. For example, the giant component never exceeds 50 percent of all the nodes in the network. This is caused by the fact that the size of a corporation influences its ability to create ties in both the board and the ownership network, because human resources and capital act as limiting factors. The size of the giant component in board networks therefore partly depends on the size of the dataset.

\subsection{Ownership network}

Links in the board network are to some extend of course the result of business relationships between firms. One example are relationships between producers and suppliers. For studies of such networks, we refer the reader to Krichene et al. (2019) and Chakraborty et al. (2018). For our purposes, the analysis of this level of connectivity would however delve too deeply into a very specific topic. However, business relationships that are more elaborate often result in some kind of shareholding or even cross-shareholding relationship. We have obtained data that reports the five largest shareholders and the percentage of shareholding for all of the firms in our sample. (This data is based on reporting required by law that is limited to the top five owners.) This might at first seem a little restrictive, yet in practice significant influence onto a company is unlikely to be performed by more than five owners. Also since this data is reported from the viewpoint of the owned company, this still results in a rather complete picture of the ownership network.

In the following, we will refer to the weighted networks based on ownership simply as the ownership networks. The ownership networks differ from the board networks by the fact that they are directed networks. The densities are however comparable, the ownership network in 2004 contains 2574 directed links, and we see a steady increase until 2013 when the network has 3695 links. The out-degree distributions of 
these networks are more skewed (see the right panel of Fig. 2), and the power-law exponents lie around 2.2-2.3.

Links in the ownership network are (with negligible exceptions) not reciprocal and tendentially hierarchical. This has to do with the legal framework for reporting ownership relations. ${ }^{3}$ When calculating degree assortativity, it therefore makes sense to report the correlation of the average out-degree of neighbors with a node's in-degree. We find that this value fluctuates around 0.3. Different from the board network, this behavior translates only into negligible clustering since short directed loops are rare. If we were to ignore directionality for a moment and calculate clustering based on undirected ownership, this changes and we observe similar local clustering as in the board network. The global clustering in this case is lower than local clustering, and this difference is likely due to the just mentioned hierarchical structures and the fact that some nodes in this network have a much higher degree (compared to the maximum in the board network). This behavior is related to the diversified shareholding of some corporations, which does not produce much clustering.

The big hubs in the ownership network are mostly insurers and securities companies. Their shareholdership in a firm is normally small, but their activity is very spread out. In fact, much of their holdings are likely on behalf of their clients. A visualization of the ownership network in 2013 is shown in Fig. 11 in the "Appendix". It shows that communities in a classical sense do not exist, or vastly overlap. Not surprisingly, large corporations like Toyota, Mitsubishi, Fujitsu, Honda, Mitsui and Nippon Steel can be classified as smaller hubs in this network.

The ownership network is very stable, about 90 percent of the links survive from each one year to the next. However, the overlap between links in the firm network and the ownership network is with about 10 percent relatively small, as is shown in the left panel of Fig. 3.

One can condition this relationship on the level of shareholding. For this reason, we have binned pairs of firms with similar ownership percentage $(N=30)$ and have calculated how many of those are also linked in the board network. ${ }^{4}$ Results are shown in the right panel of Fig. 3. We can observe that the probability of having a board link increases with ownership and passes the unconditional probability once we reach about 10 percent ownership. Interestingly, at the high end when ownership reaches 50 percent this relationship slows down and might even slightly drop. It is likely that since this represents a majority ownership, there is less demand for control by shared board members once we reach this level of ownership.

\footnotetext{
3 When we calculate the giant component of the ownership network, we therefore consider the undirected version of this network.

${ }^{4}$ For this comparison, we consider an undirected version of the ownership network. In the directed version of the network about $10 \%$ of the links are reciprocal.
} 

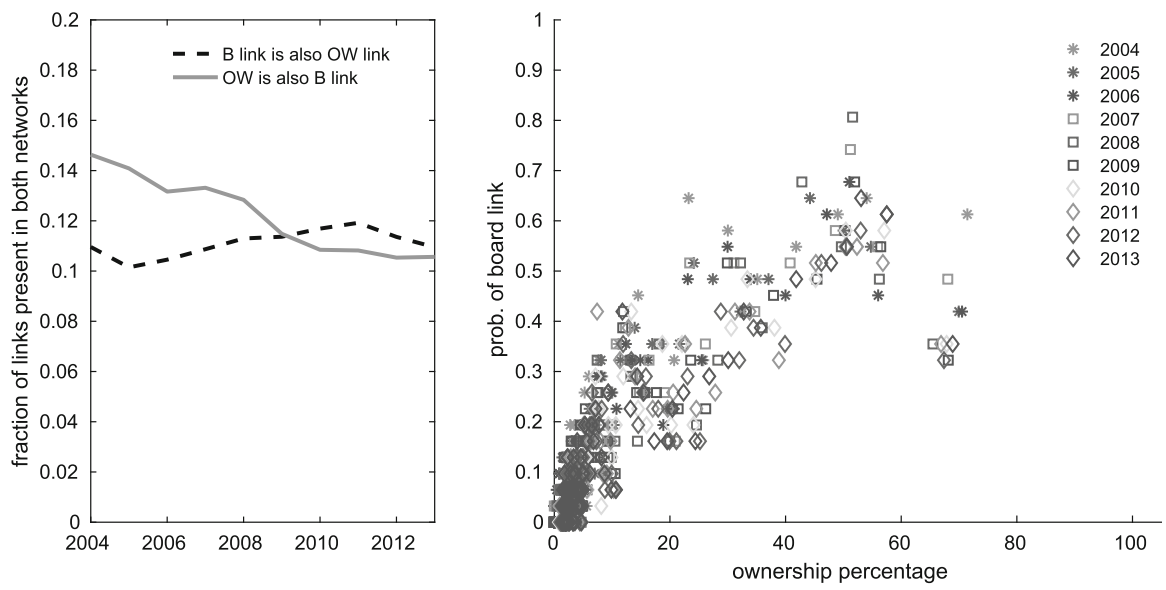

Fig. 3 Ownership statistics. The left panel shows the fraction of board links for which the respective link is also present in the ownership network, vice versa. The right panel shows the relationship between the percentage of ownership of two firms and the conditional probability of having a link in the board network. The calculation is based on subsamples of 30 firms with similar ownership

\section{Dynamics of the board network}

\subsection{Determinants of board member survival}

Since we have seen that some board members have multiple mandates, it is useful to investigate how the survival figures change when we condition the survival on the number of mandates that a board member has. These conditional survival probabilities are shown in Fig. 4. The probability for board members with one mandate differs only insignificantly from that of the entire population (83\%). The likelihood to survive increases to around $93 \%$ with another mandate, further additional mandates only lead to marginal improvements. So even if directors with multiple mandates are of course more likely to survive, one can easily see that the losses of mandates are not independent. $^{5}$

Based on these results about board member survival we can have a more detailed look at determinants of their destinies. Since the large number of board members prohibited us from collecting detailed information on each of their career paths, we have to confine ourselves to some of their basic characteristics together with details on the firms for which they work.

We can check if the role of a board member has an influence on his survival probability. We can further check if gender or the size of the company are important aspects of director survival, while we control for the number of mandates ${ }^{6}$ and age. Further, the performance of the firm should have an impact on survival. We can disentangle this

\footnotetext{
5 We can verify this by using the probability of survival with one mandate $p_{1}$ to calculate $\left(1-p_{2}\right)$, the probability that a board member with two mandates looses both of them. Assuming independence, from the probability of losing one mandate we know $\left(1-p_{1}\right)=1-0.83=0.17$ and hence $1-p_{2}=\left(1-p_{1}\right)^{2}=$ 0.0289 , which would predict a survival probability of close to $97 \%$ for managers with two mandates.

6 In particular, the log of the deviation from the average number of mandates plus 1.
} 


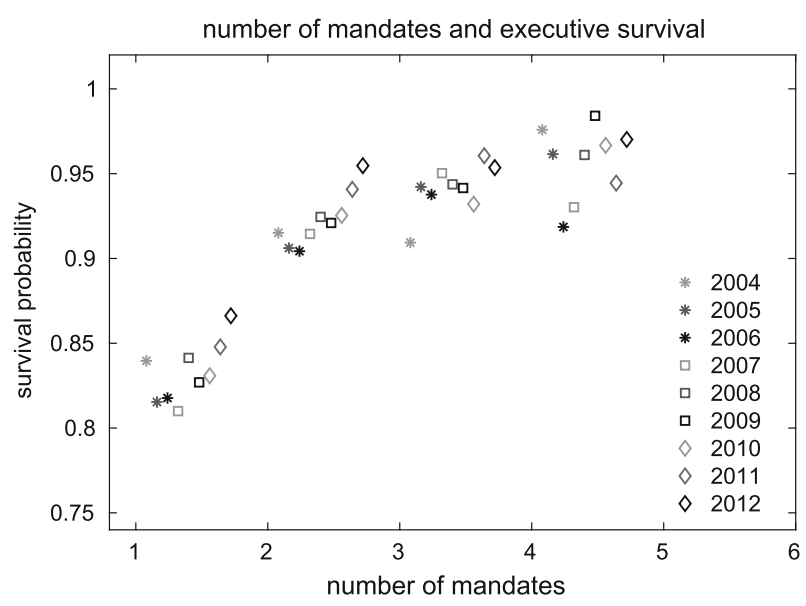

Fig. 4 Influence of number of mandates on survival. The figure shows the survival of board members with 1, 2, 3 and 4 mandates. The results are printed with an offset for the years 2004-2012

effect into two parts. First, we introduce a dummy variable for the case that a board member works for a firm that ceases to exist. Second, we calculate the difference in the market value for two consecutive years to capture the influence of the performance of firms that remain in business. ${ }^{7}$

Since survival is a binary variable this demands for a logistic regression where the observed survival or death (in the sense of leaving the data set) depends on the above mentioned variables. To confirms the robustness of the results with respect to the firm performance variables, we have also estimated the model while omitting these variables, and results are given in Table 9 in the "Appendix".

The results in Table 2 indicate that most of the variables have a significant influence on the destinies of board members, yet the explanatory power is not very large, which hints at additional unobserved effects on the level of the individual board members. In general, the results are a bit more volatile in the first 4 years where we observe more changes in the sample composition, including the financial crisis, from 2009 on the results are remarkably stable.

The delisting of a firm and the number of previously held mandates are of course the most important influences in this analysis. The impact of age is mostly negative or insignificant, as expected, with some exceptions in the first years. Only very few women are serving as board members, less than $2 \%$, and only at the end of our sample period, we see a slight tendency of higher survival. The market value (and thus also size) of a firm has a slight negative influence on survival; hence, smaller firms have slightly fewer changes in their boards. The influences of firm performance are mixed. Of course board members mostly disappear when a firm ceases to exist, but this influence is admittedly there mostly by construction. We cannot answer the question if the firm ceased to exist because of poor performance of the board or if other influences like

\footnotetext{
7 For board members with multiple mandates, these variables capture the largest firm for which they work. Data for the change in market value is available for about $80 \%$ percent of the observations. We truncate mv change at $100 \%$ to dampen the influence of outliers.
} 


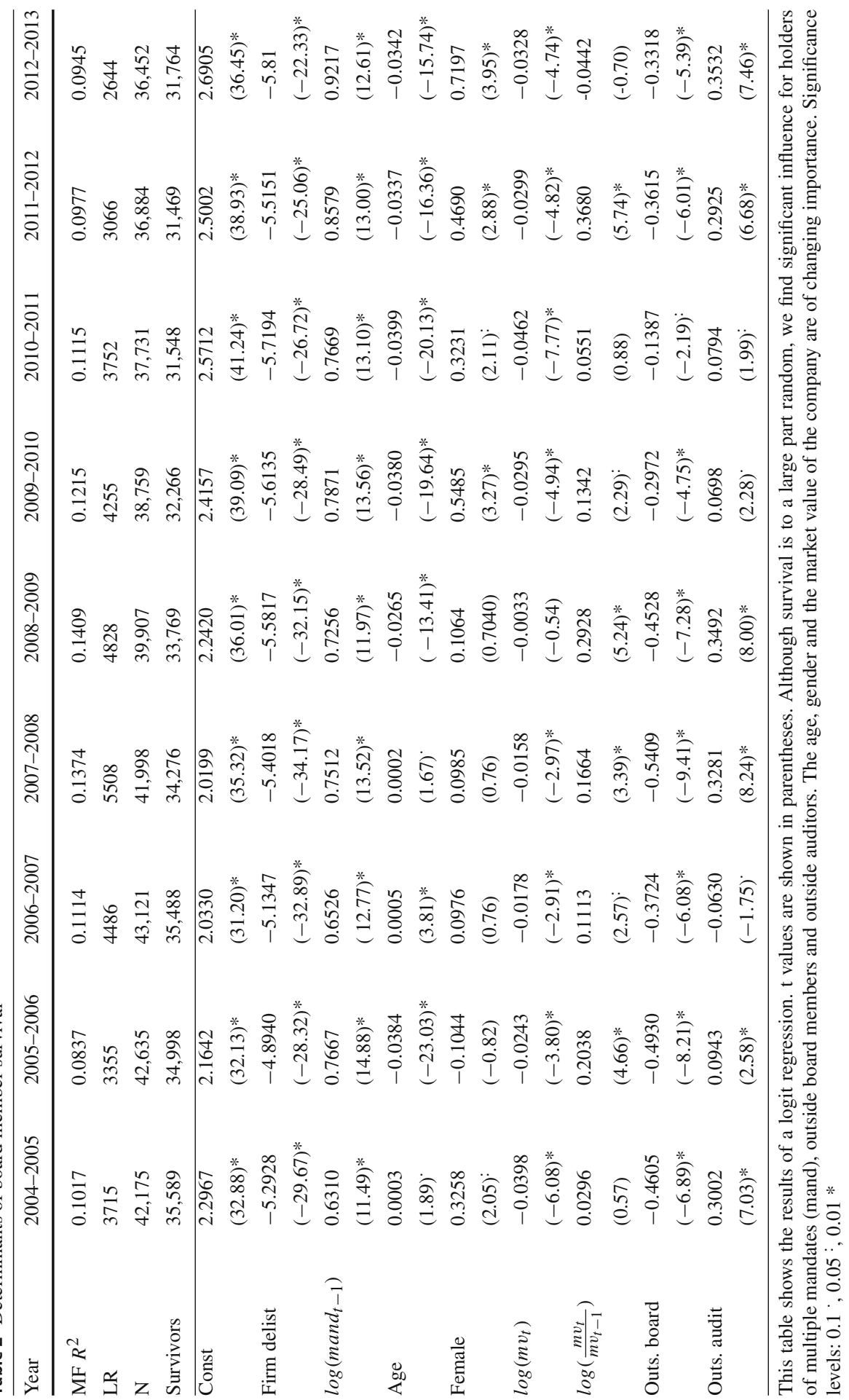


mergers or restructuring are responsible. The influence of a change in market value is significant, yet the effect is small. Hence, the performance does influence the board in general, but admittedly our dataset does not identify specific responsibilities within the board which could explain these effects in more detail.

Rather clear however are the effects for board members who are not executives. Outside board members are being dropped with a higher likelihood throughout the sample period. This intuitively make sense since they are a more dispensable part of the board. On the other hand, it is common practice to stick to an auditing company once relations are established and thus outside auditors stay on the board longer than executives. The outlier in 2006/07 for the survival of auditors is at first sight puzzling, but is in fact easily explained by the ChuoAoyama PricewaterhouseCoopers accounting scandal (Skinner and Srinivasam 2012) that lead to a temporary increase in auditor replacement. ${ }^{8}$ In addition to the results presented in the table, we have checked if the existence of ownership ties increases the probability of board member survival. We could not find proof of such a relationship.

\subsection{Tie survival}

Another question is where the persistence of the network structure in the board network comes from. If it were just a matter of board members with multiple mandates at highly capitalized firms, then we should see higher survival rates of executives at these companies. We have however seen that this is not the case. This implies that there must be mechanism of upkeep of board network ties that go beyond the existence of central board members.

For this reason, we use the same method as in Raddant et al. (2017) and compute how many links between companies are being kept from one year to the next and look into how these links are maintained if board members retire. The findings are summarized in Table 3 . We observe that only very few links are being lost because firms disappear. About $76 \%$ of the links survive from one year to the next and about $73 \%$ do so because at least one of the board members who was bridging the two boards is still there. Another $3 \%$ of links however is being kept because a new board member is replacing this function, in more than half of the cases he/she was already member of one of the boards. In any case, the board member was already a central player in the board network, with typically 2-3 mandates in the year before, much more than the average. We can thus conclude that one source of the persistence of the board network comes from the fact that board members with multiple mandates are being replaced by other board members that also hold multiple mandates.

Our findings are thus in line with those of Raddant et al. (2017) and Stearns and Mizruchi (1986) who find that about $14 \%$ of broken ties are being reconstituted by new directors. ${ }^{9}$ We cannot analyze the determinants of the reconstruction in this setting.

\footnotetext{
8 See also: The Economists, May 11th 2006, Auditors in Japan.

9 The first paper investigates time intervals of 6 years. The latter paper in fact reports almost the exact same percentage of reconstitutes links that we observe. To compare our results in Table 3 , we have calculated the percentage of reconstituted links as the ratio of links created by new $b$. member divided by the number of broken ties given by firms alive minus same $b$. member.
} 


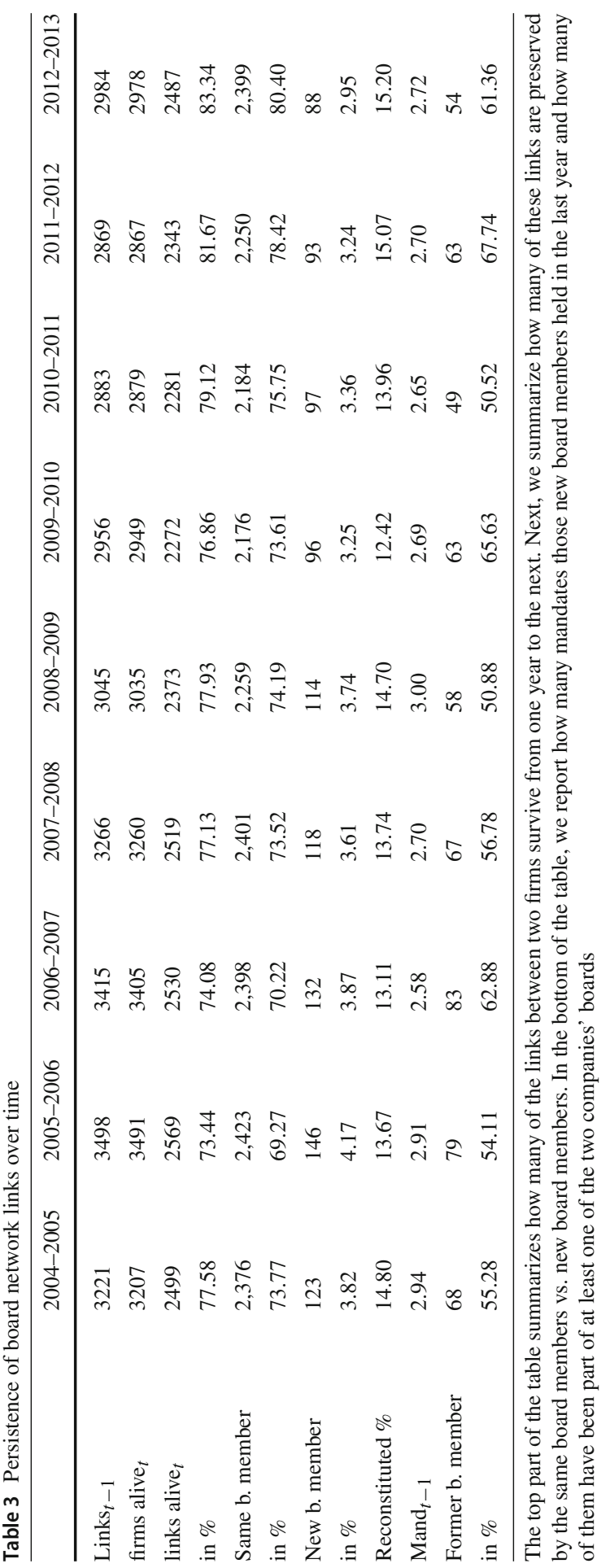



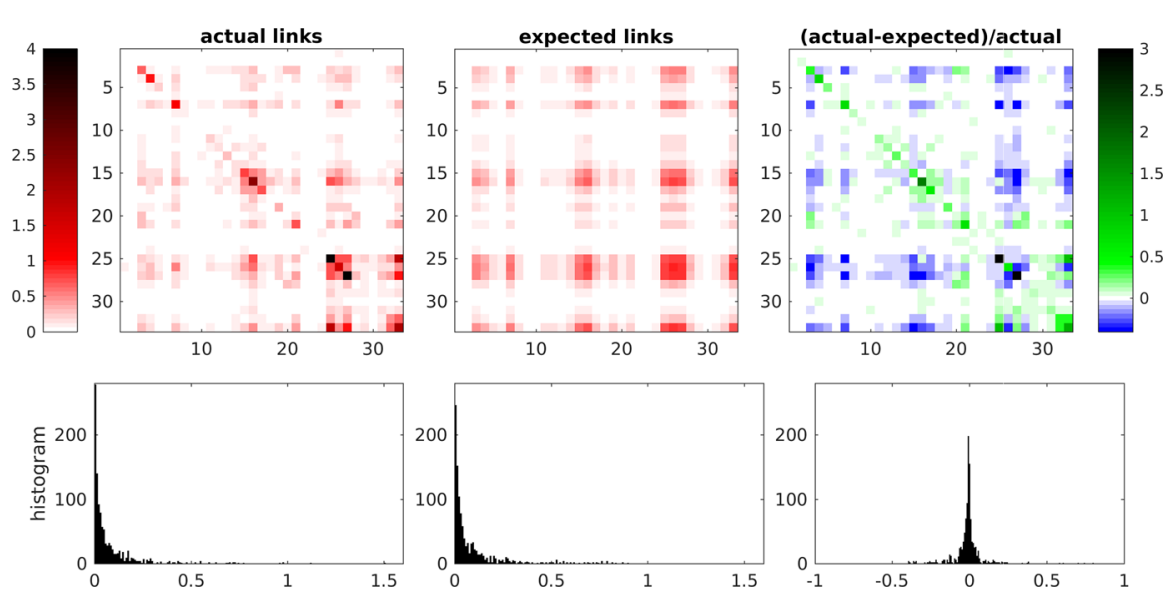

Fig. 5 Links in the board network based on sector classification. The top left panels show how the links are distributed within and between sectors of the economy (in percent). The middle panel shows the expected distribution given the number of firms in each sector and the respective average board sizes. The right panel shows a comparison. The bottom panels show matching histograms (abscissae clipped). The calculations are based on the 10-year averages

Yet, we can contribute to the debate about link reconstitution (Westphal et al. 2006) by confirming that in fact only a fraction of interlocks are being reconstructed. We can add that nevertheless this fraction contributes dis-proportionally to the overall connectivity, the persistence of the network structure over time and the tightly knitted networks between the most central board members.

\section{Structure of the board network}

When we speak about structure in the board network, one of the first questions has to be whether there are preferences with respect to the type of firms that are linked. One can ask if firms from certain sectors are more connected than others. For this reason, a closer look at the 33 TOPIX sector classifications is useful.

A complete list of the sector classification together with some statistics can be found in Table 12 in "Appendix". The number of firms per sector varies, the sectors with the most number of companies are services, wholesale trade and retail trade (No. 33, 26 and 27). A color-coded matrix that shows the links between firms based on their sector affiliation is shown in the left panel of Fig. 5. When we assume that the number of links between sectors should only depend on the number of firms in each sector and the average number of board members we can calculate an expected number of links, which is shown in the middle panel. Overall, the qualitative resemblance between these two structures is rather good. The main difference is found on the main diagonal where we find more within-sector links than expected. On the other hand, there are cases where we find slightly fewer links than expected between sector from rather different parts of the economy like trade $(26,27)$ versus the traditional manufacturing 
and construction industry $(15,16,3)$. Another observation is a slight preference for links to the financial sector (28-31), which needs further investigation.

In order to quantify effects in the board network, we test two important hypotheses: The first one is to evaluate if firms tend to have more links to firms from the same sector. This would speak in favor of hiring board members that might bring some special expertise. The second hypotheses is that ties to the financial industry are reflected in additional ties. This would for example speak in favor of relationships of firms to a main bank who sends a board member to monitor the bank's exposure (see Lamb and Roundy 2016; Gulati and Gargiulo 1999; Kanamitsu 2013; Davis et al. 2003)

We have employed an exponential random graph model (Strauss and Ikeda 1990) to estimate these effects in the giant connected component of the board network. We assume that a firm's likelihood to form ties to another firm is proportional to the product of the number of board members of the two firms. We further assume that the level of ownership relations influence ties. ${ }^{10}$

In other words, our estimation tests the assumption that links within the same sector and to the financial sector are over-represented against the hypotheses that links are randomly distributed between firms and that their likelihood just depends on the number of members on the respective boards and ownership relationships.

We also investigate the possibility that there is an endogenous tendency of connected firms to share additional partners by estimating the so-called geometrically weighted edgewise shared partner statistic (gwesp), see Hunter (2007). This variable accounts for endogenous clustering that appears generally and is not explained by other variables. We did not find other significant endogenous network statistics in our network, which is likely due to the relative sparsity of our network (compared, for example, with the findings for the Japanese production network in Krichene et al. 2019). ${ }^{11}$

Our results are shown in Table 4 and basically confirm both our hypothesis. There is a slight but constant tendency of links to the financial industry and a more obvious tendency for links to firms with the same TOPIX sector code. The latter effect is declining gradually. Hence, these two effects influence the structure of ties in the board network, but the results also show that the majority of links do not depend on them (and also not on board or firm size). We further confirm that there is a slight overlap between the ownership and the board network. However, this effect is small and roughly similar to that of within-sector ties. Some increase in the significance of the ownership effect and some decrease for the within-sector effect is observed over time. This might originate from the increase in ties in the ownership network and could be interpreted as a slight shift from informal ties in the board network toward more formal ties that incorporate also significant shareholding. The gwesp variable

\footnotetext{
10 The board size variable is measured as the deviation from its mean divided by 100 . Ownership is a percentage value.

11 We estimate gwesp with a fixed decay parameter of 0.25 for higher-order shared partners. We have also investigated the triangle statistics of our network but have found that estimation is plagued with model degeneracy. Estimating gwesp or triangles should however lead to very similar results in our case, despite the different conditioning of both statistics for identifying clustering. We note that our model aims at estimating the influence of observable economic determinants on connectivity in the board network. A comparisons of alternative endogenous mechanisms is outside the scope of this paper.
} 


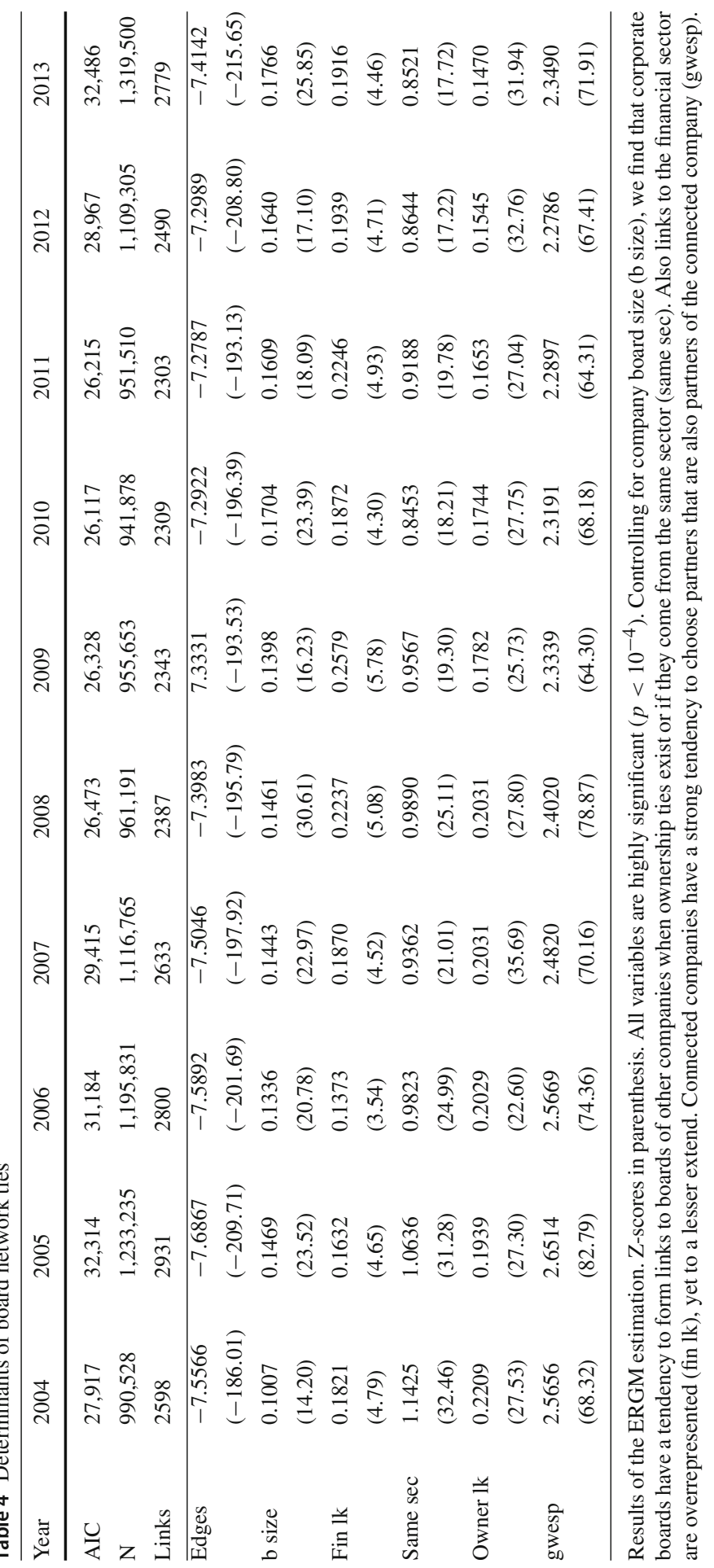


is significantly positive, indicating a tendency for clustering that is not explained by exogenous effects.

To check for the robustness of our results we have also estimated a model without endogenous clustering (gwesp) as well as one with fixed effects for each sector. Both did not influence our qualitative results, fixed sector effects only lead to negligible improvements in the fit. We also estimated versions with sector-to-sector interaction variables, but found that the gains in fit are small relative to the increase in the number of variables (measured by the AIC, material upon request). We have analyzed the goodness-of-fit of our model and found that simulated models based on our estimates are in agreement with the empirical network, see Fig. 12 and Table 10 in "Appendix".

\section{The role of outside board members and multiple mandates}

We have already mentioned that the composition of Japanese corporate boards still differs noticeably from that in other western countries. Therefore, it is useful to have a look at changes in the composition of corporate boards, in particular the role of outside board members.

First, it is worth mentioning that the share of women on the boards of Japanese corporations is still very low. Even in 2013 less than $2 \%$ of board members are women. More change has happened with respect to outside board members. From 2004 until 2013, their share has doubled to $9.6 \%$, for details see Table 11 in the "Appendix".

Our dataset allows us to look more closely into which board rooms these additional outside members go. Therefore, we perform a Poisson regression in which our dependent variable is the number of outside board members in a firm. The number of outside members should depend on the size of the board, which is also a proxy for the size of the firm (which we therefore cannot account for in isolation). We test for the influence of the composition of a firm's shareholders (see also Mian and Nagata 2015) and we test if the appointment of outside directors is related to the profitability of a firm, i.e., if the firm's return on assets is related to the number of outside board members. For the case of shareholdership, the data allows to differentiate between the percentage of shares held by financial institutions, by security companies, by other corporations and held by foreign corporations (the remainder is held by individual investors). Data on the distributions of shareholdership is not available for some smaller companies, which limits the data set to 2432 to 2706 observations dependent on the year.

The results are summarized in Table 5. We show the results separately for each year, always with and without sector dummy variables. We calculate a pseudo $R^{2}$ value by calculating the ratio of correct predictions of the number of outside board members using the predictions rounded to integer values.

As expected, the number of outside board members varies with board size. More interestingly, the shareholder characteristics are highly significant. A high fraction of foreign shareholders increases the likelihood of having outside board members noticeably. The influence of shares held by other corporations is also significant, though slightly weaker.

These results hold when we include dummy variables for the most populated sectors according to the TOPIX classification. These variables add slightly to the explanatory 


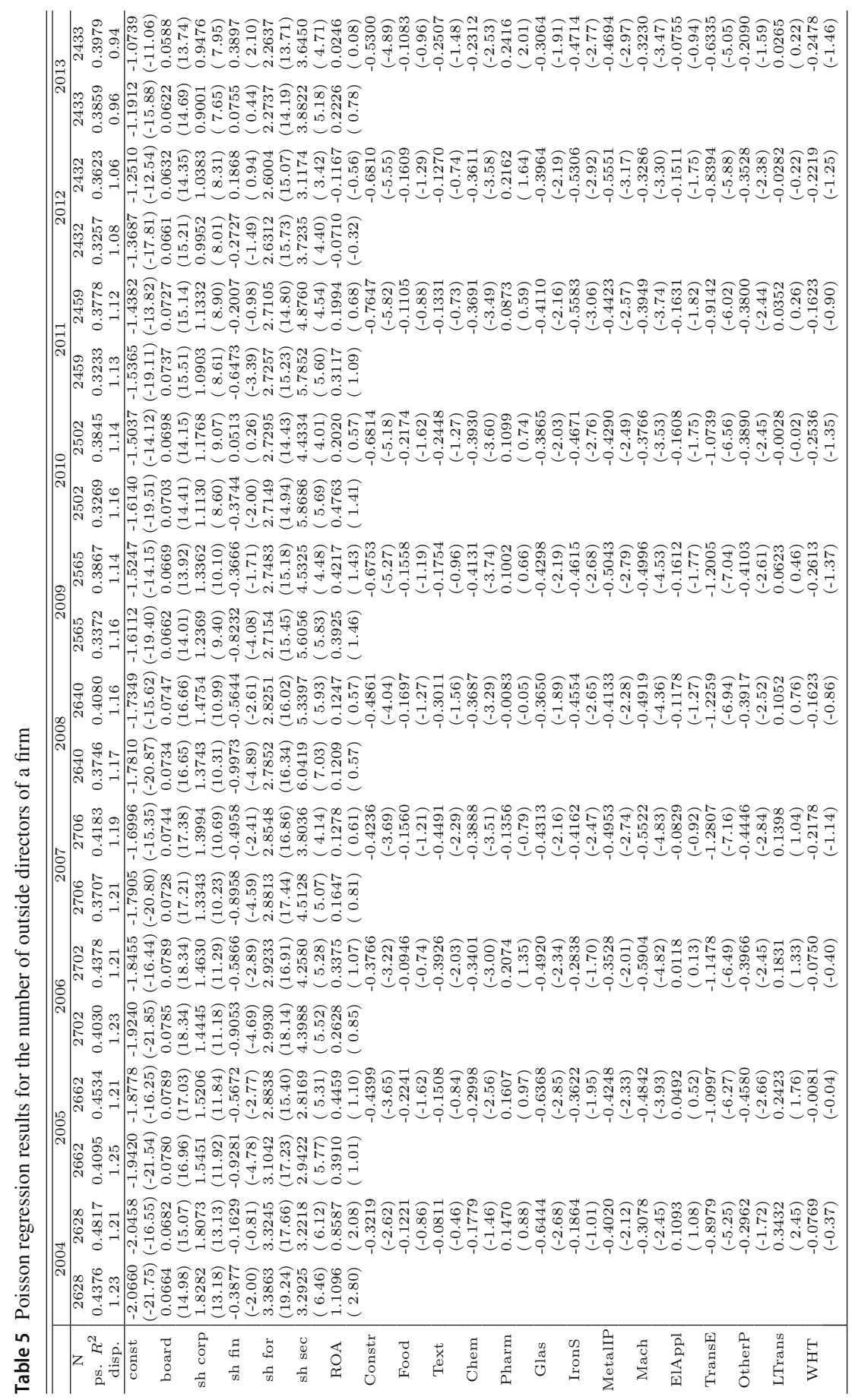




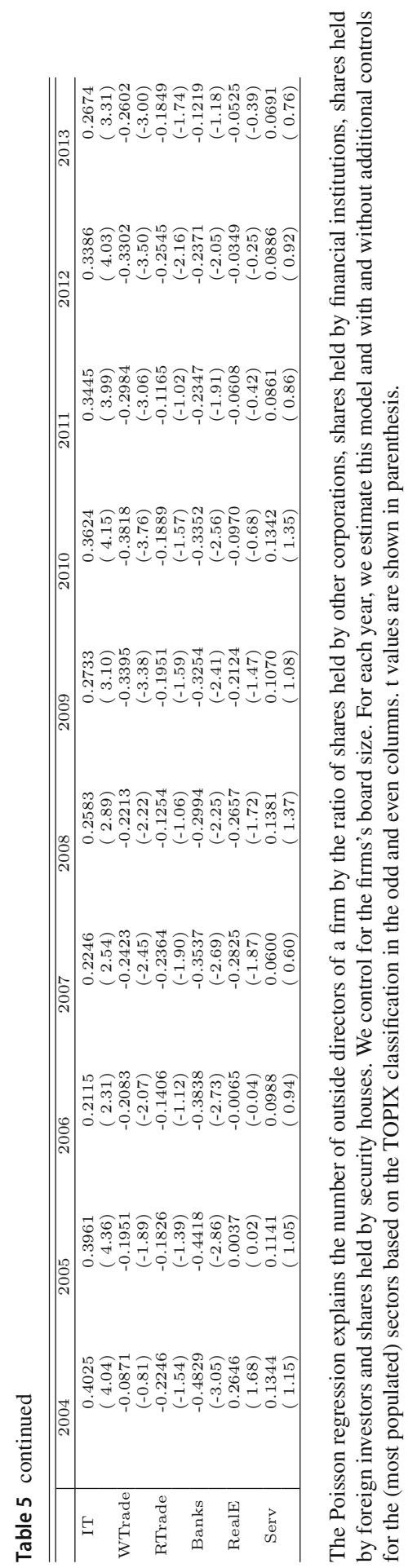

Springer 
power since in some sectors outside board members are still not that common. This includes firms from the sectors construction, glass, machinery, transportation equipment and (for most of the time) banks. On the other side of the spectrum, we find the IT industry, which for the entire sample period employs significantly more outside board members than the average.

The number of outside board members is on average higher at firms with higher profitability, yet this relationship is weak and fading over time. ${ }^{12}$ Hence, while in the 2000s outside board members might have been an indicator for board efficiency and profitability, the wider adoption of outside board memberships has removed this relationship over time.

In general, our results are mostly in line with similar findings by Agrawal and Knoeber (1996) and Duchin et al. (2010), despite methodological differences. We can confirm that outside board membership has a sector-specific component and we observe that an increase in the number of outside board members does not necessarily lead to better performance. A likely explanation for the time variation of our results is that in the early phase of our sample, it was easier to find outside board members that had low costs in acquiring information about the firm they were appointed by (and were therefore effective) and that at the later stage of our sample are larger share of outside directors was appointed that served more of a window-dressing purpose.

\section{Networks and firm profitability}

\subsection{Firm growth and connectivity}

Over the ten years that our sample covers, some firms have, as discussed earlier, ceased to exist. Many others have seen profound changes in their business models or have for other reasons gained or lost in influence and size. We will therefore follow the 1798 firms that have survived and for which consistent data is available on their performance. We have calculated the percentage growth in total assets over the course of the 10 years and have grouped the firms into the top $25 \%$, middle $50 \%$ and bottom $25 \%$ according to this criterion.

In Fig. 6, we show how these different groups develop. We observe that the firms from the weakest performing group do not only loose in terms of total assets but that these firms also loose connections in the board network and the ownership network (top left and bottom right panel). The top $25 \%$ on the other side have a high connectivity in both networks which is further growing, partially by hiring more outside board members and other board members with multiple mandates. ${ }^{13}$

Arguably, some of these developments are natural consequences of the growth and shrinkage of firms. (For more details, see also Fig. 14 in the "Appendix", which shows

\footnotetext{
12 Data on the ROA is not available for all the firms in the sample. As a robustness check, we have therefore alternatively estimated the model with reduced sample sizes of about two thirds of the firms. We have also estimated the model with the full sample while omitting the ROA variable. In both cases, the qualitative results were identical to those presented in Table 5 (material upon request).

13 Twelve firms which showed abnormal changes in total assets, mainly due to mergers and acquisitions, have been removed from this analysis.
} 

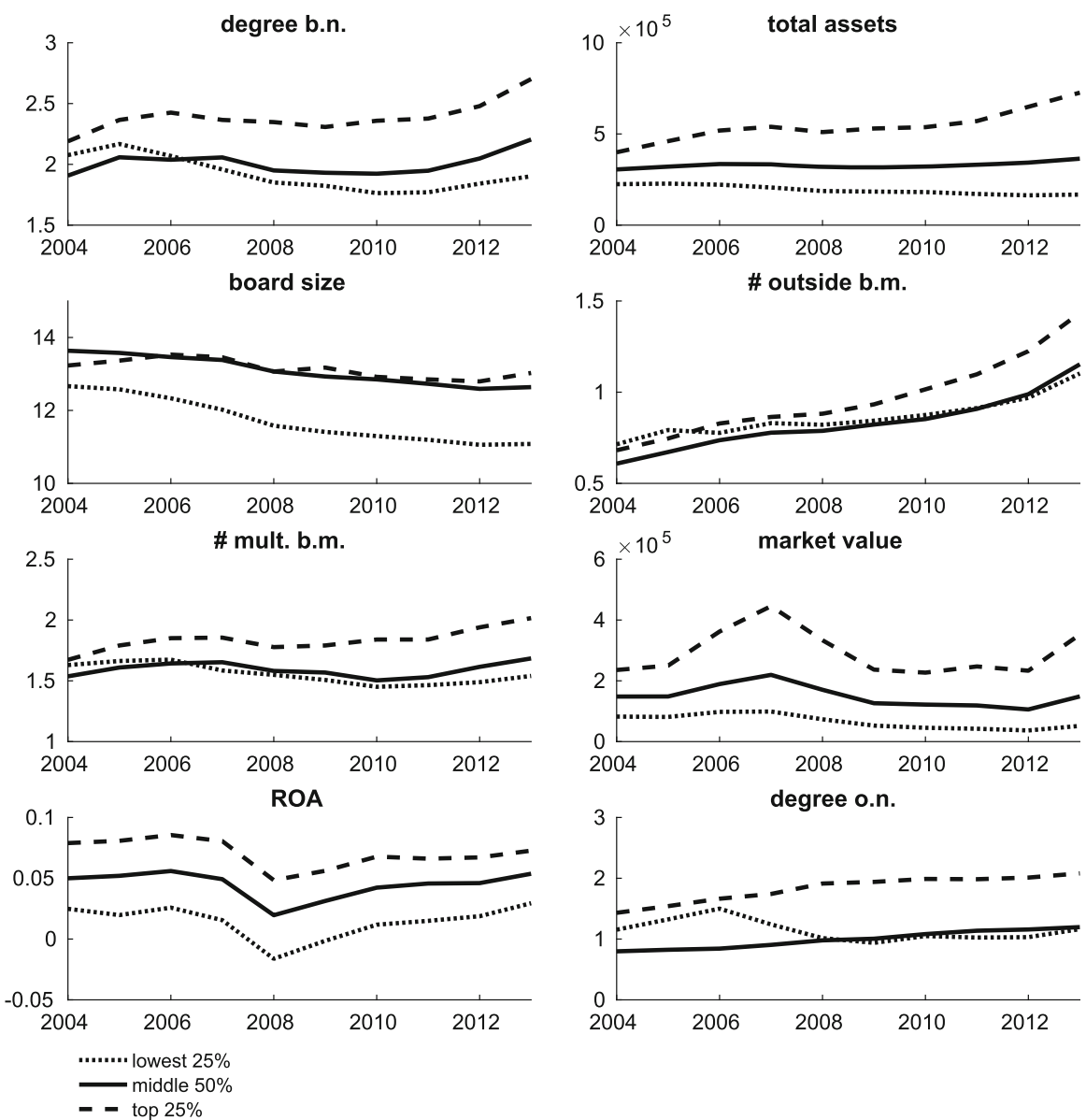

Fig. 6 Firm growth over time. This figure shows how the top $25 \%$ of firms with the highest total asset growth have developed compared to the lowest $25 \%$ and the rest. The figures show that firms that shrink (lowest growth) also loose connections in the board network and ownership network. Firms that grow gain interorganizational ties and gain more outside board members

the relationship of connectivity with other firm characteristics.) The fact however that the worst performing $25 \%$ of firms had a connectivity above average in the board network and the ownership network in 2004, which then successively dropped, suggests that some conditional feedback might exist from connectivity to profitability and growth. Those firms who performed worst lost more ties during the financial crisis than everybody else. This suggests that not the amount of ties but their quality is related to growth and profitability. We will elaborate on this in the following section.

\subsection{Determinants of profitability}

The structure of the top layer management of a corporation and how it is connected with the management of other corporations has implications for the long run success of a 
company. Executives or other board members who can bring in experience from outside can be very valuable to navigate economic downturns or restructuring processes. On the other hand, board members who serve as a mere transmission channel for the needs of affiliated companies can slow down the effective management of a company (see also Davis and Cobb 2010; Carpenter and Westphal 2001). Similar effects occur in the case of ownership or equity ties between corporations. Connected firms can profit from these connections if they support a chain of value generating activities that would be hard to achieve without them. When ties exist for the mere sake of diversification of business activities the effects are often ambiguous (see also Anjos and Fracassi 2015).

In the case of Japan corporate ties however have a special history. Firm conglomerates, often refereed to as keiretsu, used to have a huge influence on the economic system until the middle of the 20th century. Traces of them are still visible today, even if many argue that the economic downturn of the 1990s dissolved most. Studies on the long-run success of these conglomerates find that these structures go at hand with within-group interventions and risk sharing, a process that in general has been found to significantly lower the return on assets of conglomerate members. We will follow up on this finding and analyze if there are effects from firm connectivity on profitability by using variables from the board and ownership network together with some control variables. Similar to the work by Lincoln and Gerlach (2004), we measure profitability by the return on assets (ROA) and we use the total assets and the ratio of loans to total assets as controls. ${ }^{14}$ Data on these key financials is not consistently available for all the firms in our sample. This limits the sample for this part of the analysis to around 2000 firms in each year. ${ }^{15}$

Since the number of potential variables that describe network relationships, centrality, local connectivity or clustering is almost endless, we choose to break this analysis down into two steps. First, we employ a machine learning algorithm that we feed with data of the potential variables. From this process, we learn which variables seem to have an impact on the ROA. It also helps to identify variables that might interact. In any case, the results from the machine learning algorithm are then used to construct dummy variables which significance can be analyzed within a regression analysis.

We found that a regression tree model delivers satisfactory results in the first step. The output of this model consists in a regression tree, a hierarchical structure where at each branch the dataset is split into two parts depending on the value or state of the most important variable. An example of such a tree is shown in Fig. 13 in the "Appendix". We have run the tree model separately for all the ten years of our dataset, and we have evaluated which variables, thresholds of variables, and combinations of variables repeatedly appear in the regression trees for all the ten years. We have supported this by calculating the importance scores for all the variables for all ten years. These results are shown in Fig. 7.

\footnotetext{
14 We found that the ROA is the variable that works best for a large sample comprised of firms from different sectors, including variables like sales into our model would necessitate either a much more complex model or a drastically reduced sample size.

15 We omit firms from the analysis which report a ROA that is outside the range $-20 \%<$ ROA $<25 \%$ since such results are typically not the result of continuing business activity.
} 


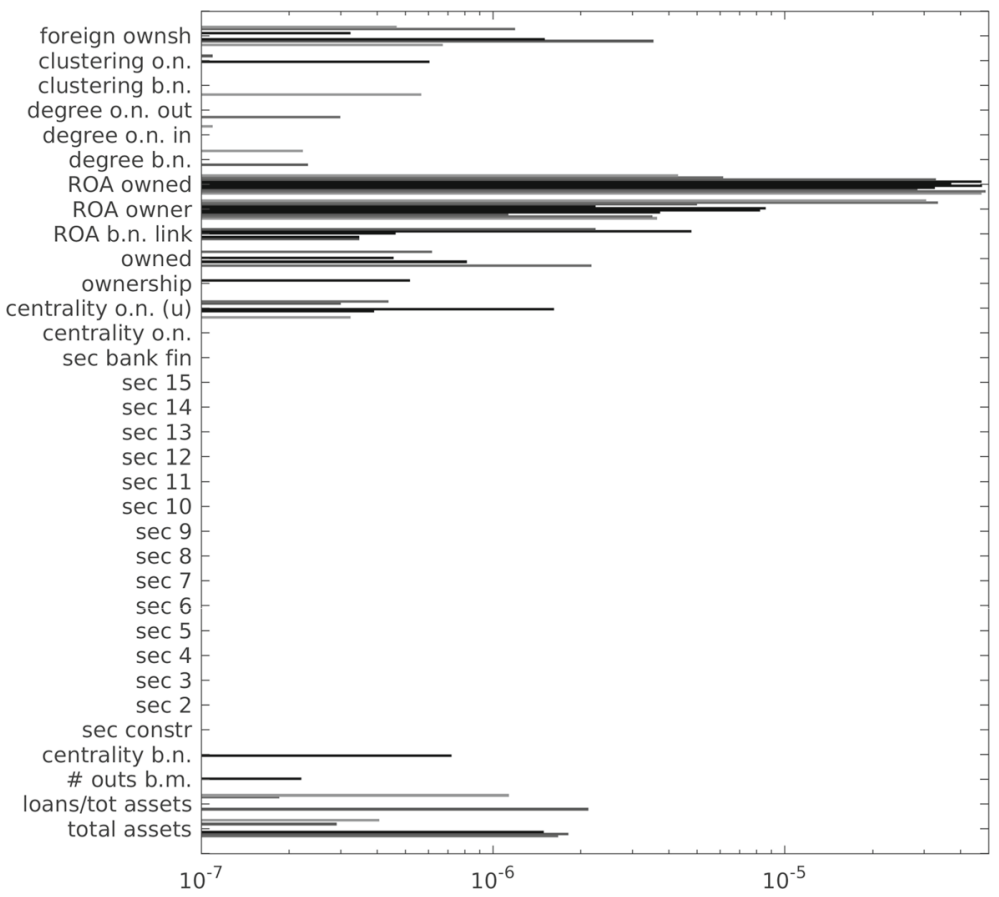

Fig. 7 Importance of variables in regression tree. The figure shows the importance scores of all our variables for all 10 years in a combined bar plot and on a log scale. Variables that are not used at any node in the regression tree will have a score of zero, while the score of other variables depends on the relative improvement to describe the data when the variable is used as either a primary or surrogate splitter

We have tested the following variables: log total assets, loans to total assets, number of outside directors, log eigencentrality in board network, sector dummies, log eigencentrality in ownership network, log eigencentrality in undirected ownership network, total ownership of other companies, fraction of company owner by other companies, average ROA of company linked to in board network, ROA of largest owner (min $3.8 \%$ ownership), average ROA of companies owned (min $2 \%$ ownership), ${ }^{16}$ degree in board network, in- and out-degree in ownership network, local clustering in board and ownership network, and foreign share ownership.

From this analysis, we learn that the ROA of owned firms as well as the ROA of the main owner have most influence on the firms' ROAs. The regression trees show us in fact even more, namely that these two variables often appear as two successive branches in the tree with predicted ROAs significantly different from the mean when both, the ROA of the owner as well as the average ROA of owned firms are greater than 3.5 percent. Also other variables from the ownership network have some importance, namely total ownership and the total share owned by other firms as well as centrality

\footnotetext{
16 The threshold of $2 \%$ is required to filter out diversified investments of institutional investors and other shareholders without significant influence on the owned firm. Filings for large shareholders are legally required at 5\% ownership in Japan. In practice, this leads to many cases of shareholding slightly below this threshold which is why we chose a threshold of $3.8 \%$.
} 
(which are of course related). The degree itself is almost never important in any network. What is further interesting is that also the ROA of a firm which is linked by a shared board member is sometimes a significant influence.

In a second step, we can now test the significance of the influence of links in the ownership and board network by estimating the determinants of ROA. Since only some of the firms have a connection in the board and ownership network, we cannot use the ROA of connected firms as a variable directly. Also, in the case of the ownership network, both directions of ownership seem to be important. Hence, we set up two dummy variables. The board link dummy is 1 if the mean of the ROA of connected firms is larger than the mean of all firms plus 0.2 times the standard deviation. The dummy for the ownership network is 1 if both, the average ROA of owners and of owned firms is larger than the mean ROA minus 0.3 times the standard deviation. ${ }^{17}$ Hence, it signals that a firm is not sandwiched in between a badly performing owner and badly performing partly owned firms. We further test for the influence of the position of a firm in the ownership network by adding the variable total ownership, which describes the cumulative percentage shares held by other companies in the ownership network and degree/total assets, the number of companies of which a firms holds shares of divided by total assets. These specifications are chosen to make sure that these two variables do not correlate with total assets but give a measures of ownership relative to the size of a firm.

We now estimate three versions of this model. ${ }^{18}$ The first version uses only the just mentioned variables without any further differentiation for sectors or years. Since the thresholds for our ownership and board link ROA variables depend on the yearly averages of the ROA, a pooling for all 10 years should in principal be possible. The results for this model are shown in the left column of Table 6. Since the financial crisis of 2008 has probably let to more than just minor fluctuations it makes of course sense to employ individual constants for each year. As we can see, this does not change the estimation results much, yet it improves the explained variance quite a bit. Finally, we can add variables to classify the most populated Topix sectors. This should help to explain differences in ROA which are caused by sector-specific effects. We use 12 dummy variables for the sectors, yet in the table, we only show the most important ones. We note that the financial sector is a merged category that contains banks, insurances, and firms offering other financial services.

Interestingly, our analysis shows that ownership relations generally lead to slightly (yet significantly) lower ROAs. There are however two exceptions from this. Positive effects can be found when both the owner and the (partly) owned firms are profitable (signaled by the variable ROA owner net). Significantly positive effects can also be found from links in the board network (ROA board net), if connected firms have above average profitability. ${ }^{19}$

\footnotetext{
17 This results in a still slightly positive ROA. Note that this threshold level is derived from the regression tree analysis, but we now express it in terms of the mean and the standard derivation to accommodate for slight changes over time.

18 We note that the distributional properties of the data require a robust regression. This mean that all our assessments of significance are based on t-distributed errors.

19 As a robustness check we have performed the same regression on a yearly basis and found similar results, although the $R O A$ variables were not significant in all years. We have also left out the control variables total
} 
Table 6 Determinants of ROA

\begin{tabular}{|c|c|c|c|c|c|c|}
\hline Model & Simple pool & & Year dumm & & Year and se & \\
\hline$R^{2}$ & 0.0464 & & 0.0794 & & 0.1107 & \\
\hline$N$ & 20,942 & & 20,942 & & 20,942 & \\
\hline Const & 0.05467 & $(10.56)^{*}$ & & & & \\
\hline Const $1-10$ & & & . & & . & \\
\hline Total assets & 0.00077 & $(1.58)$ & 0.00058 & $(1.22)$ & 0.00150 & $(2.97) *$ \\
\hline Loans/tot assets & -0.08289 & $(-10.89)^{*}$ & -0.07927 & $(-10.58)^{*}$ & -0.08662 & $(-11.04)^{*}$ \\
\hline Tot owned & -0.00166 & $(-7.41)^{*}$ & -0.00168 & $(-7.63)^{*}$ & -0.00132 & $(-5.92)^{*}$ \\
\hline Degree/tot assets & -0.05415 & $(-2.00)^{:}$ & -0.04806 & $(-1.80)$ & -0.06166 & $(-2.31)^{:}$ \\
\hline ROA owner net & 0.01647 & $(4.32)^{*}$ & 0.01696 & $(4.52)^{*}$ & 0.01502 & $(4.06)^{*}$ \\
\hline ROA board net & 0.00820 & $(4.14)^{*}$ & 0.00816 & $(4.19)^{*}$ & 0.00695 & $(3.61)^{*}$ \\
\hline Sec constr & & & & & -0.01773 & $(-4.93)^{*}$ \\
\hline Sec chem & & & & & -0.00047 & $(-0.88)$ \\
\hline Sec machinery & & & & & 0.00317 & $(0.34)$ \\
\hline Sec elec appl & & & & & -0.00674 & $(-2.20)^{*}$ \\
\hline Sec bank finance & & & & & -0.02019 & $(-3.23)^{*}$ \\
\hline Sec IT comm & & & & & 0.01848 & $(5.49)^{*}$ \\
\hline Sec pharma & & & & & 0.02718 & $(4.55)^{*}$ \\
\hline Sec 7-16 & & & & & . & \\
\hline
\end{tabular}

This table shows the estimation results for three different models of influences on the return on assets. The simplest model in the left column only considers the main variables. The model in the middle column considers a dummy variable for each year. The model in the right columns considers a year dummy and 16 dummies for sectors, of which the results for the seven most important ones are given. $t$ statistics based on $\mathrm{t}$ distributed errors are given in parenthesis. Significance levels: $0.1^{\circ}, 0.05^{\prime}, 0.01^{*}$

At last, the results on the effects of ownership deserve a closer look. We want to investigate if instead of referencing to connected firms' ROA structural features could be responsible for our results.

First of all, one could argue that in some cases we might see effects from minority shareholder relationships. Some authors claim that minority shareholders can be disadvantaged against controlling shareholder who enjoys private access. This can impact firm valuation and profitability (see, e.g., Guedes and Loureiro 2006; Claessens et al. 2002).

Second, our general result on negative effects from ownership relations is in fact in line with many studies on diversification. Although diversification as an instrument of risk management is often successful, many studies show that corporations which invest into companies that operate outside of their own area of expertise are likely to

\section{Footnote 19 Continued}

assets and loans/TA, this changes the results for the sector dummies but leaves other results qualitatively unchanged. Including further network measures does not improve the model and can lead to problems in the estimation since these variables tend to be related to the existing measures of degree. We note that foreign share ownership is correlated with total assets and also partly explained by the sector dummies and can thus not be included into this estimation. 

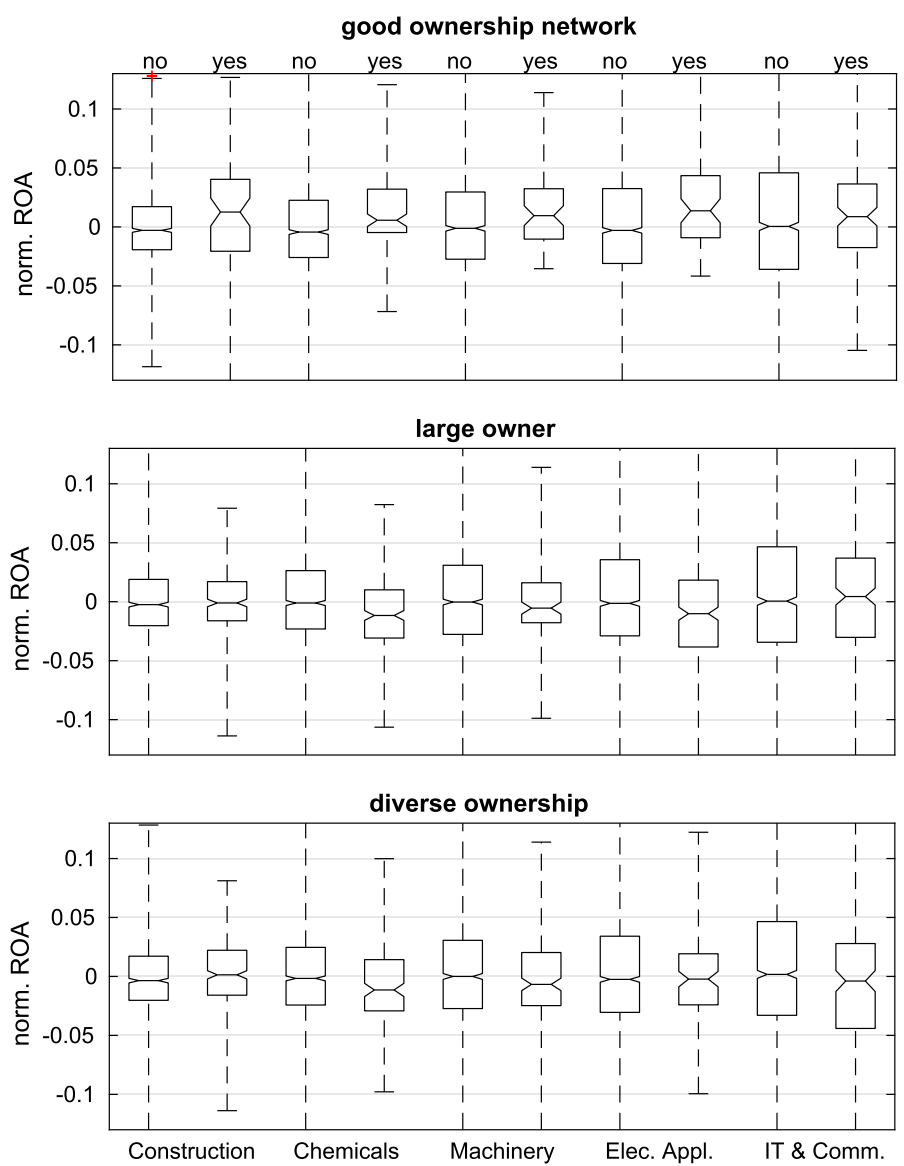

Fig. 8 Influences of ownership structures. This figure shows the differences in normalized ROA for firms from five large sectors and for three comparisons. The top panel compares firms with a 'bad' versus a 'good' ownership network. The middle panel compares firms with and without a large owner with at least 20 percent shareholdership. The bottom panel compares firms that have diversified through ownership of a company in another sector versus firms which do not diversity

negatively influence their own profitability (Berger and Ofek 1995; Schommer et al. 2019; Kawakami 2017).

In order to judge if any of these effects are related to our findings, we will look at subsamples of companies from the five most populated sectors, namely construction, chemicals, machinery, electrical appliances and IT and communications. We will compare firms with regard to the above-mentioned effects based on their ROA, which we normalize by the yearly group averages.

The results are presented in Fig. 8. We show box plots for three different comparisons for firms from five different sectors. The top panel shows the differences in the normalized ROA for our good ownership dummy variable as defined in our regression analysis and serves as a reference point. The averages of the bar plots labeled as 'no' 
and 'yes' are almost always significantly different, thus confirming that the results of our regression analysis can in principal be confirmed without further control variables.

We can now look at differences in between the same firms that might be caused by minority shareholdership. The middle panel show a comparison where the firms are now grouped by the criterion whether they have an owner that controls at least 20 percent of the company. The results for this comparison are ambiguous. Firms from the sectors chemicals and electrical appliances do in fact have a significantly lower normalized ROA when they have one very large owner, for firms from other sectors this effect cannot be confirmed.

Finally, we group the firms by asking whether they own at least one percent of some other firm that is active in a sector different from their own. This aims at checking effects from diversification. At a first glance the results, presented on the bottom panel, appear unsystematic. For some sectors the difference is positive, for others negative. However, a pattern can be found once we go back to the sector-based dummy variables from our regression analysis in Table 6. In those sectors, where the average ROA is above or similar to the economy average (chemicals, machinery, IT) the average normalized ROA is lower for corporations which diversify to other sectors. For the two sectors where the average ROA is below economy average (construction, electrical appliances) diversifying into other sectors yields a slightly higher normalized ROA. These results are admittedly not in all cases significant, yet they show an interesting tendency. The benefits of diversification might depend on what the heritage of a corporation is and whether they can in the long run divert funding into activities in more lucrative fields.

Coming back to the question if our previous regression results are possibly remnants of minority shareholding or diversification effects, we can conclude that these do not explain our findings. The network effects on profitability that we have identified in the ownership network and through corporate board interlocks are of a more general kind and are caused by interdependencies of profitability rather than ownership relations alone. Our results can thus be viewed as complementary to that of Zona et al. (2018). While in their study they have found effects of board interlocks that depend on characteristics of the ego firm in a network, we have found effects that mainly depend on characteristics of the alter firms.

\section{Conclusions}

In this paper, we have analyzed dependencies between firm performance and the networks of board members and ownership from different viewpoints. We found that the survival of board members mostly depends on their role in the board. The feedback from the development of the market value on board members survival is small. Broken ties in the board network are reconstituted in many, but by far not in all cases. Yet, their reconstitution process contributes to the preservation of network structure and ties between the most central directors.

For the overall network structure, we observe a tendency for links within the same sector and an mild influence of ownership ties on board interlocks. The number of outside directors is increasing, yet their number depends mostly on the sector of the firm 
and the influence of foreign shareholders. Their relationship with firm performance is mostly spurious.

We observe that variation in firm growth is connected to variation in connectivity in both the board and the ownership network. Most importantly, interaction effects in firm performance are found in both networks. Firms that are connected to peers with above average profitability are themselves more profitable.

Further research is needed on these effects of interorganizational ties. This however necessitates more fine-grain information on financial ties, including information on the main bank and borrowing relationships, as well as the inclusion of production networks. More research is also needed on the dynamics of board composition, especially the career paths of individual executives and the appointments of female board members.

Acknowledgements We thank Chieko Takahashi for help in compiling the board network data.

Funding Open Access funding enabled and organized by Projekt DEAL.

Data Availability Data available from Toyo Keizai, Nikkei Needs and Thompson Reuters Datastream. The authors do not have permission to share data.

\section{Declarations}

Funding Partial funding by JSPS KAKENHI, JP20K01751

Conflict of interest The authors declare that they have no competing interest.

Open Access This article is licensed under a Creative Commons Attribution 4.0 International License, which permits use, sharing, adaptation, distribution and reproduction in any medium or format, as long as you give appropriate credit to the original author(s) and the source, provide a link to the Creative Commons licence, and indicate if changes were made. The images or other third party material in this article are included in the article's Creative Commons licence, unless indicated otherwise in a credit line to the material. If material is not included in the article's Creative Commons licence and your intended use is not permitted by statutory regulation or exceeds the permitted use, you will need to obtain permission directly from the copyright holder. To view a copy of this licence, visit http://creativecommons.org/licenses/by/4.0/.

\section{Appendix}

See Figs. 9, 10, 11, 12, 13 and 14, Tables 7, 8, 9, 10, 11 and 12. 


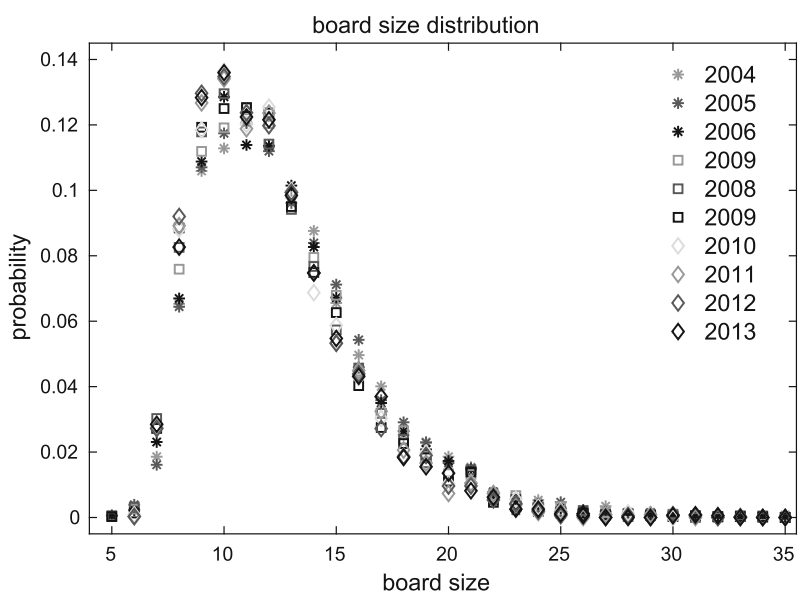

Fig. 9 Distributions of board size. The distribution of the board size shows only little variation over time. Since the board size is mostly determined by company size it shows a tail which for $x>15$ shows similarity to a power-law 


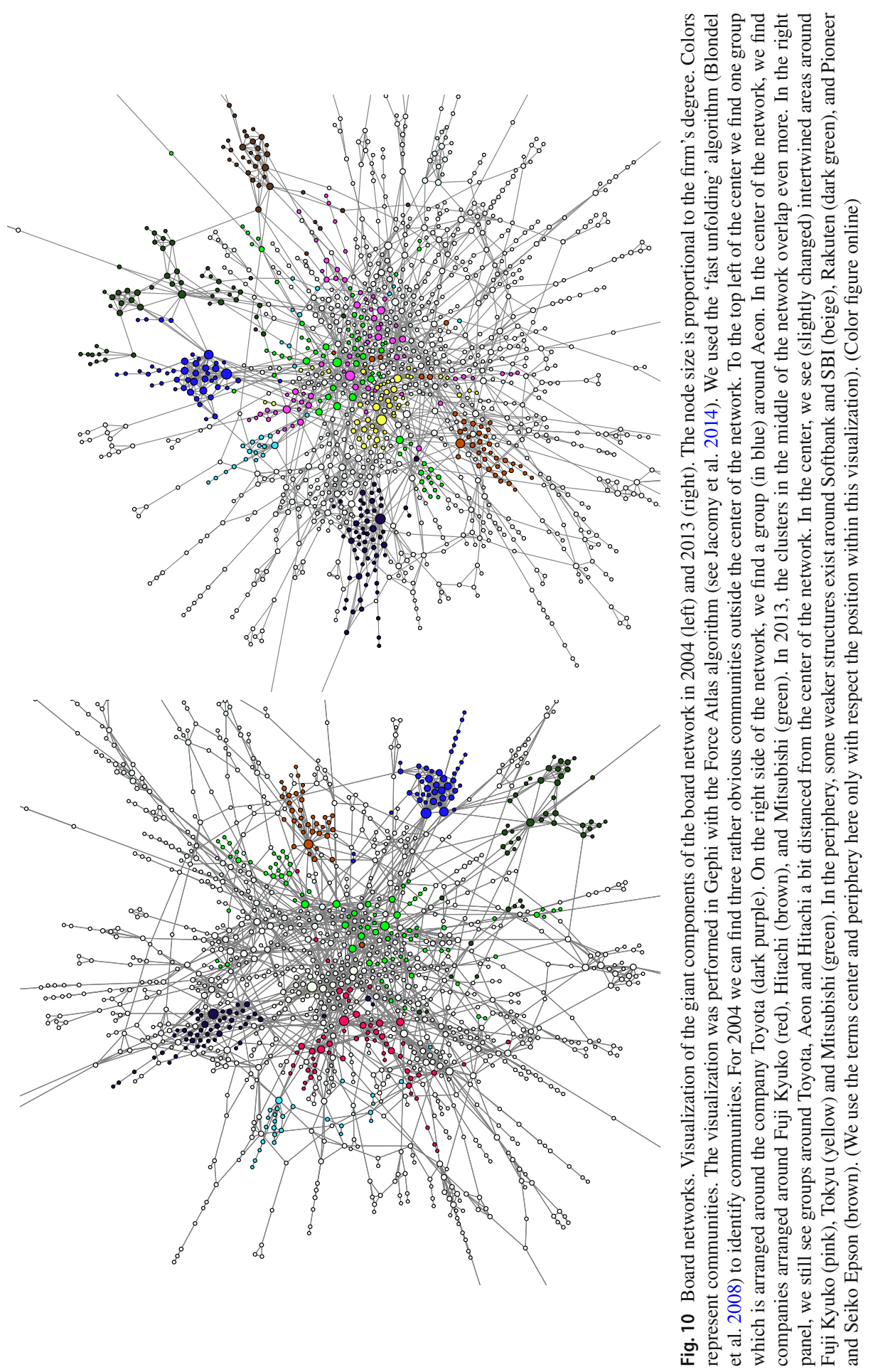




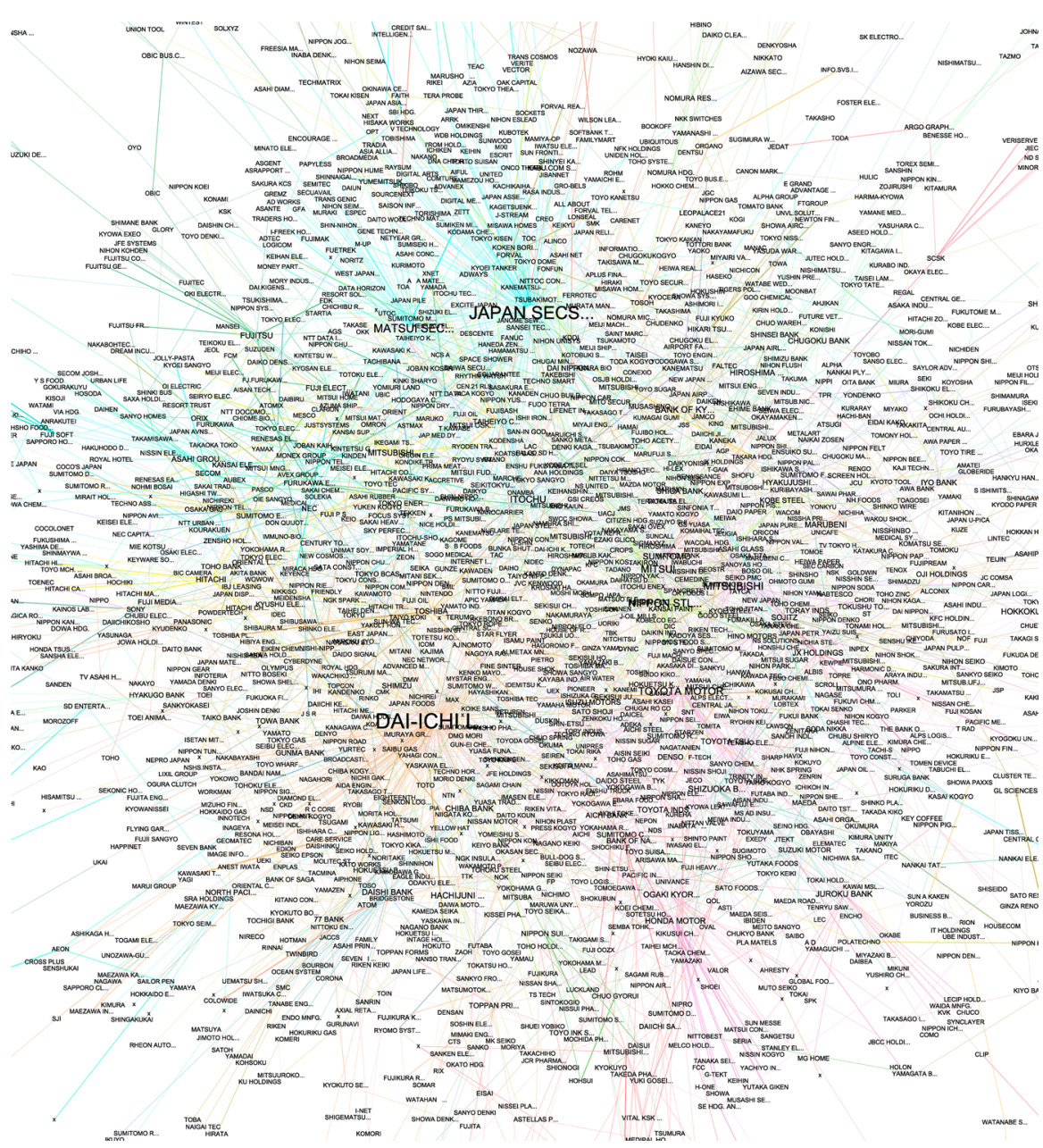

Fig. 11 Ownership network in 2013. This visualization shows the ownership network. The label size is proportional to the number of links. Color coding has been used to highlight the (overlapping and weak) communitiy structures. The vizualisation is again based on the Force Atlas algorithm and the 'fast unfolding' algorithm for community detection. (Color figure online)
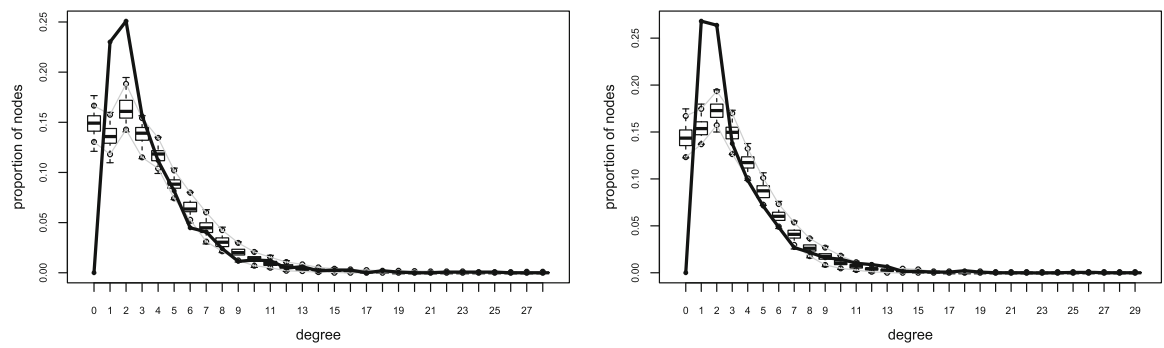

Fig. 12 Goodness of fit for degree distribution. This figure shows the degree distribution for 2007 (left) and 2010 (right) together with that of simulated networks based on estimation results. The degree distributions are in reasonable allignment for $k \geq 3$ 


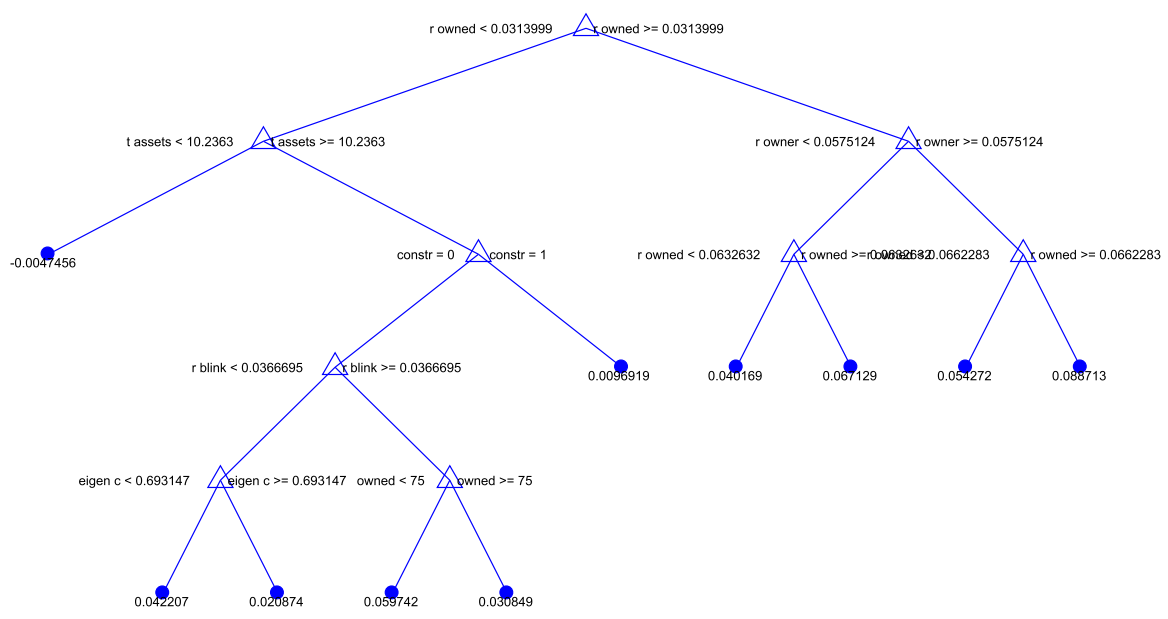

Fig. 13 Regression tree for 2010. This example shows prototypically the results of the regression tree analysis. Branches are labeled with the split variable and the split point value. End leaves show the expected resulting ROA for firms that fall into the category that is defined by the splits in the tree strucure 

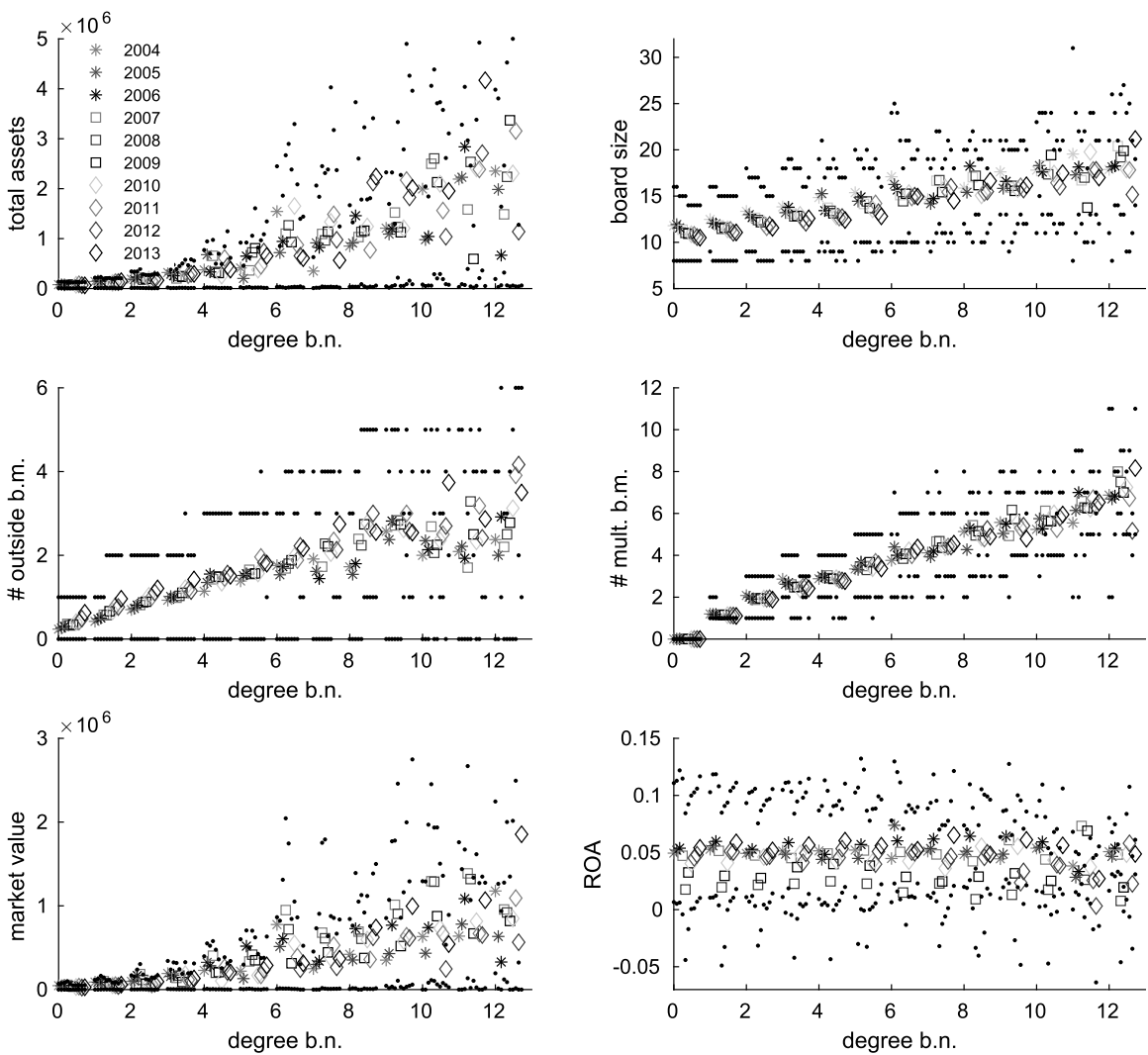

Fig. 14 Board connectivity and firm characteristics. This figure shows how different characteristics scale with the number of links in the board network. The averages for different years are printed with an offset. Black dots show the $75 \%$ interval for each year 
Table 7 Board member survival

\begin{tabular}{llllllllll}
\hline & $t+1$ & $t+2$ & $t+3$ & $t+4$ & $t+5$ & $t+6$ & $t+7$ & $t+8$ & $t+9$ \\
\hline 2004 & 0.8438 & 0.6855 & 0.5588 & 0.4508 & 0.3840 & 0.3175 & 0.2659 & 0.2263 & 0.1989 \\
2005 & 0.8209 & 0.6685 & 0.5402 & 0.4542 & 0.3774 & 0.3155 & 0.2697 & 0.2345 & \\
2006 & 0.8230 & 0.6665 & 0.5615 & 0.4601 & 0.3854 & 0.3282 & 0.2858 & & \\
2007 & 0.8161 & 0.6862 & 0.5665 & 0.4669 & 0.3976 & 0.3448 & & & \\
2008 & 0.8462 & 0.6987 & 0.5779 & 0.4866 & 0.4230 & & & & \\
2009 & 0.8325 & 0.6886 & 0.5807 & 0.4997 & & & & & \\
2010 & 0.8361 & 0.7065 & 0.6109 & & & & & & \\
2011 & 0.8532 & 0.7395 & & & & & & & \\
2012 & 0.8714 & & & & & & & & \\
\hline
\end{tabular}

This table shows the survival probability of board members from one year to every other year based on the information in the Toyo Keizai database and our identification method described in Sect. 2.1

Table 8 Firm survival

\begin{tabular}{llllllllll}
\hline & $t+1$ & $t+2$ & $t+3$ & $t+4$ & $t+5$ & $t+6$ & $t+7$ & $t+8$ & $t+9$ \\
\hline 2004 & 0.9750 & 0.9517 & 0.9180 & 0.8792 & 0.8482 & 0.8219 & 0.8004 & 0.7847 & 0.7730 \\
2005 & 0.9771 & 0.9423 & 0.9000 & 0.8683 & 0.8410 & 0.8194 & 0.8030 & 0.7906 & \\
2006 & 0.9650 & 0.9226 & 0.8907 & 0.8620 & 0.8385 & 0.8212 & 0.8088 & & \\
2007 & 0.9563 & 0.9233 & 0.8943 & 0.8691 & 0.8508 & 0.8377 & & & \\
2008 & 0.9660 & 0.9360 & 0.9092 & 0.8898 & 0.8760 & & & & \\
2009 & 0.9692 & 0.9417 & 0.9218 & 0.9067 & & & & & \\
2010 & 0.9716 & 0.9513 & 0.9355 & & & & & & \\
2011 & 0.9791 & 0.9630 & & & & & & &
\end{tabular}

This table shows the probability of survival for the firms from one to every other year, based on the existence of the stock identifier 


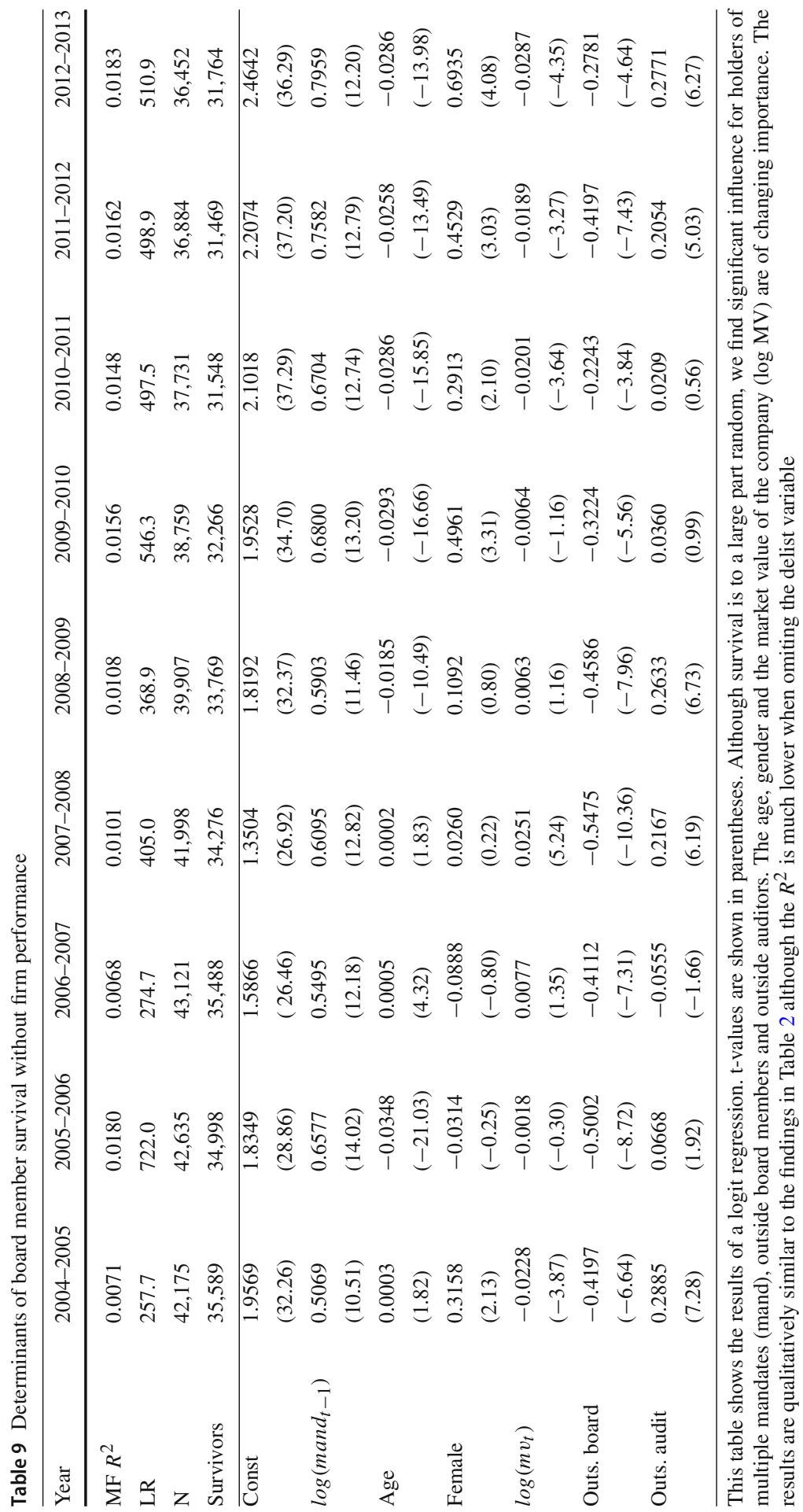


Table 10 Goodness of fit for model

\begin{tabular}{lllllllllll}
\hline & $\begin{array}{l}2007 \\
\text { Empirical }\end{array}$ & Min & Avg. & Max & P & $\begin{array}{l}\text { Empirical } \\
\text { Empin }\end{array}$ & Avg. & Max & P \\
\hline Edges & 2303 & 1993 & 2281 & 2624 & 0.76 & 2633 & 2256 & 2693 & 3060 & 0.78 \\
b size & 1036 & 609 & 959 & 1464 & 0.64 & 1356 & 1067 & 1555 & 2039 & 0.62 \\
Fin lk & 343 & 275 & 342 & 404 & 1.00 & 372 & 289 & 373 & 453 & 0.82 \\
Same sec & 377 & 304 & 363 & 450 & 0.58 & 467 & 392 & 488 & 564 & 0.74 \\
Owner lk & 5766 & 4464 & 5361 & 5913 & 0.16 & 6095 & 5504 & 6154 & 6678 & 1.00 \\
gwesp & 1607 & 1248 & 1583 & 1930 & 0.68 & 2008 & 1601 & 2083 & 2452 & 0.80 \\
\hline
\end{tabular}

This table shows the statistics of networks generated based on the model estimates against the empirical (fitted) networks for 2007 and 2010. While the simulated models show some variability in the statistics, we observe that the average of the statistics are in agreement with the empirical data. The p-statistics confirm that the empirical network is not significantly different from the simulated ones based on this statistics 


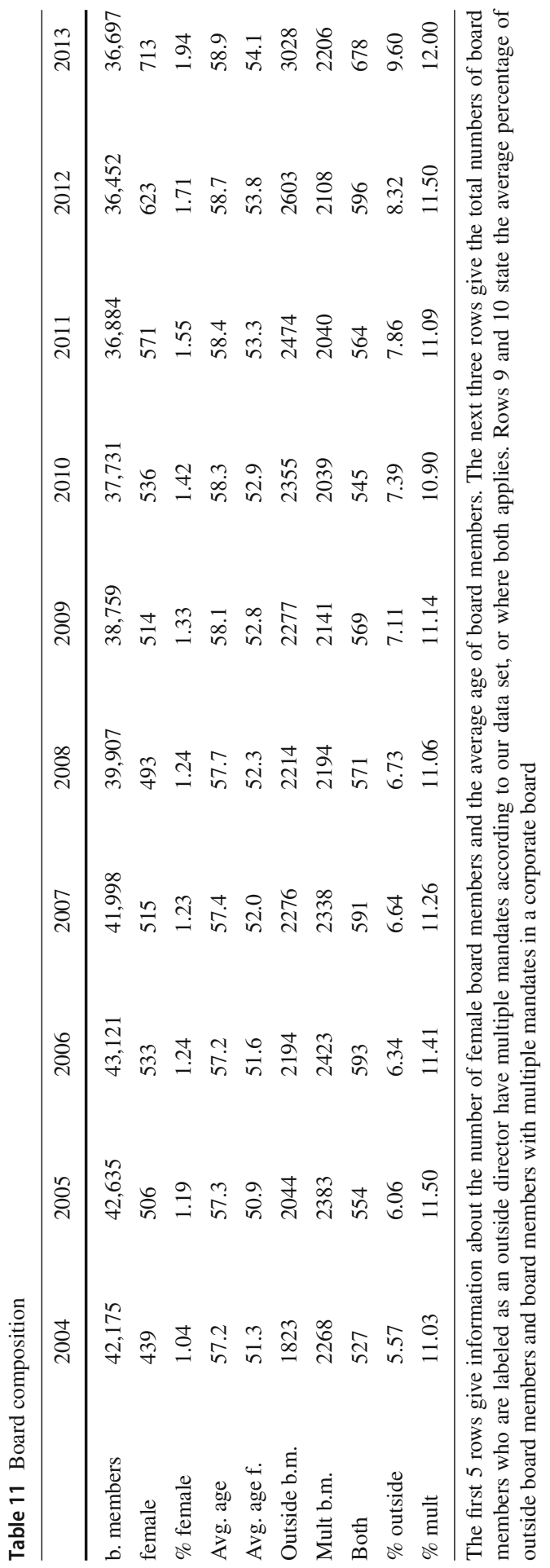




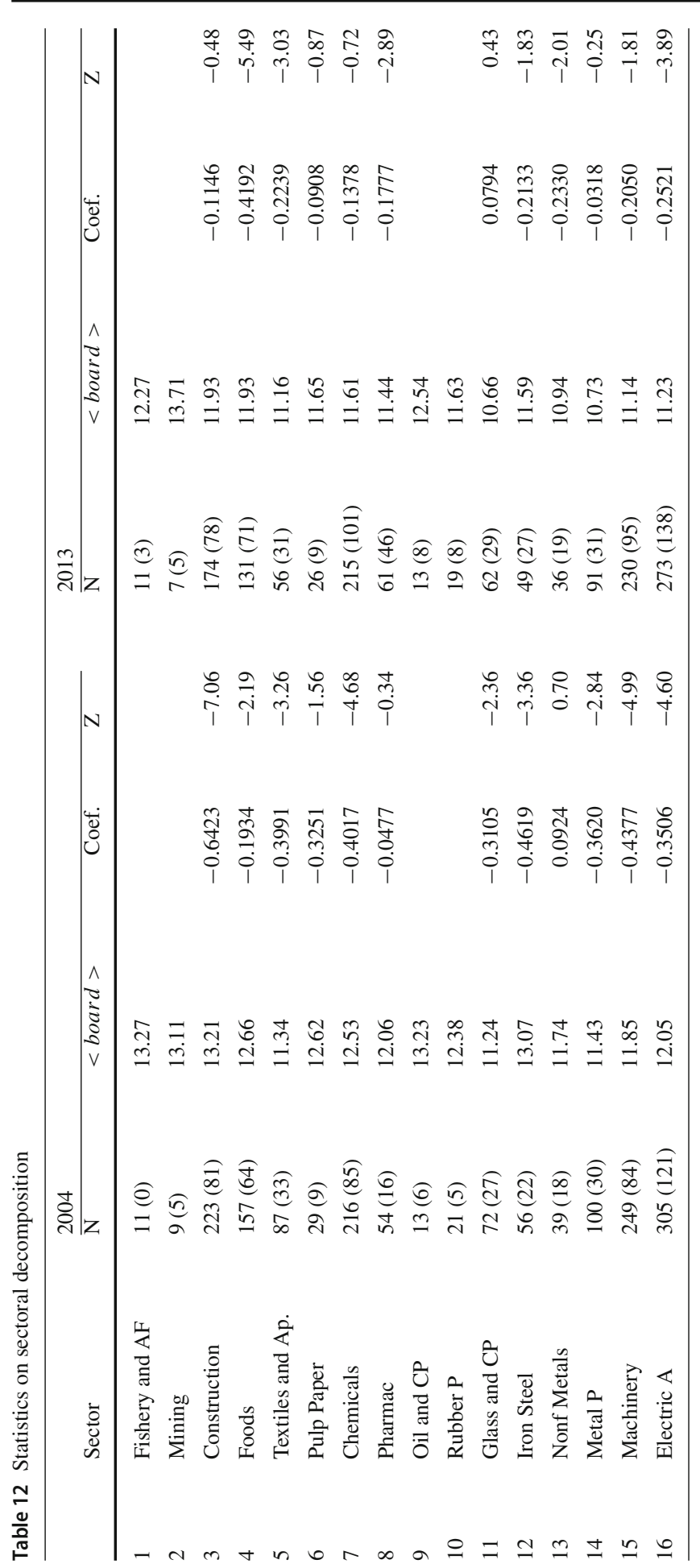




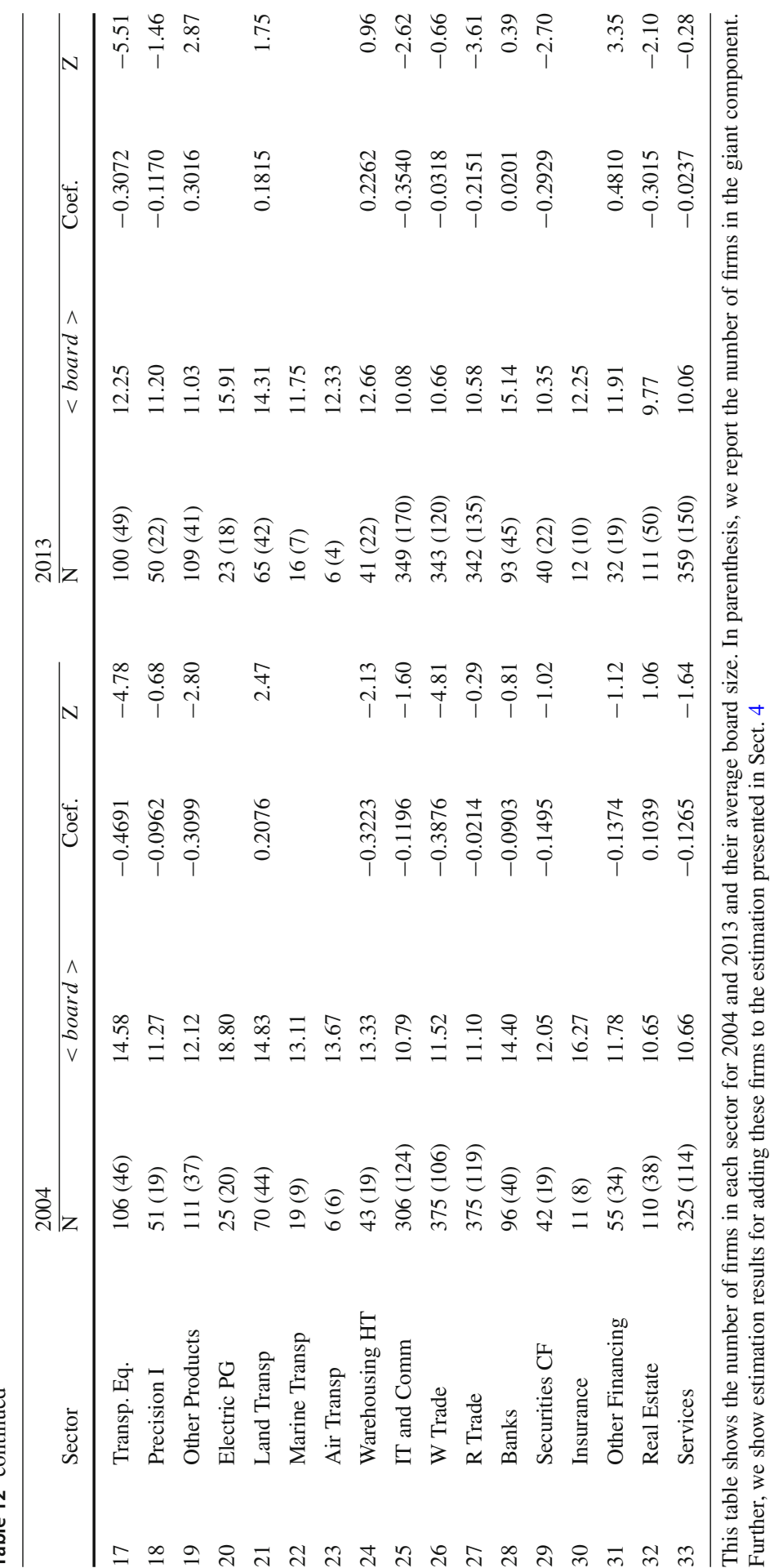




\section{References}

Acemoglu D, Carvalho V, Ozdaglar A, Tahbaz-Salehi A (2012) The network origins of aggregate fluctuations. Econometrica 80(5):1977-2016

Agrawal A, Knoeber CR (1996) Firm performance and mechanisms to control agency problems between managers and shareholders. J Financ Quant Anal 31(3):377-397

Ahern KR (2013) Network centrality and the cross section of stock returns. SSRN, 2197370

Anjos F, Fracassi C (2015) Shopping for information? Diversification and the network of industries. Manage Sci 61(1):262-183

Aobdia D, Caskey J, Ozel NB (2014) Inter-industry network structure and the cross-predictability of earnings and stock returns. Rev Account Stud 19:1191-1224

Barroso-Castro C, del Mar Villegas-Perinan M, Casillas-Bueno JC (2016) How boards internal and external social capital interact to affect firm performance. Strateg Org 14(1):6-31

Battiston S, Catanzaro M (2004) Statistical properties of corporate board and director networks. Eur Phys J B 38:345-352

Bellenzier L, Grassi R (2014) Interlocking directorates in Italy: persistent links in network dynamics. Econ Interact Coord 9:183-202

Berger PG, Ofek E (1995) Diversification's effect on firm value. J Financ Econ 37:39-65

Bizjak J, Lemmon M, Whitby R (2009) Option backdating and board interlocks. Rev Financ Stud 22(11):4821-4847

Blondel VD, Guillaume J-L, Lambiotte R, Lefebvre E (2008) Fast unfolding of communities in large networks. J Stat Mech Theory Exp 10

Buchanan J, Deakin S (2009) In the shadow of corporate governance reform: change and continuity in managerial practice at listed companies in Japan. In: Whittaker DH Deakin S (eds) Corperate Governance and managerial Reform in Japan. Oxford UP, pp 28-69

Cai Y, Dhaliwal DS, Kim Y, Pan C (2014) Board interlocks and the diffusion of disclosure policy. Rev Account Stud 19:1086-1119

Carpenter MA, Westphal JD (2001) The strategic context of external network ties: examining the impact of director appointments on board involvement in strategic decision making. Acad Manag J 44(4):639_ 660

Chakraborty A, Kichikawa Y, Iino T, Iyetomi H, Inoue H, Fujiwara Y (2018) Hierarchical communities in the walnut structure of the Japanese production network. PLoS ONE 18(8)

Chiu P-C, Teoh SH, Tian F (2013) Board interlocks and earnings management contagion. Account Rev 88(3):915-944

Claessens S, Djankov S, Fan JPH, Lang LHP (2002) Disentangling the incentive and entrenchment effects of large shareholdings. J Finance 57:2741-2771

Conyon MJ, Muldoon MR (2006) The small world of corporate boards. J Bus Finance Account 33(9):13211343

Dalton DR, Dalton CM (2011) Integration of micro and macro studies in governance research: CEO duality, board composition, and financial performance. J Manag 37(2):404-411

Davis GF, Cobb J (2010) Resource dependence theory: past and future. research in the sociology of organizations. Res Sociol Org 28:21-42

Davis GF, Yoo M, Baker WE (2003) The small world of the American corporate elite, 1982-2001. Strateg Org 1(3):301-326

Devos E, Prevost A, Puthenpurackal J (2009) Are interlocked directors effective monitors? Financ Manage 38:861-887

Duchin R, Matsusaka JG, Ozbas O (2010) When are outside directors effective? J Financ Econ 96:195-214

Guedes J, Loureiro G (2006) Estimating the expropriation of minority shareholders: results from a new empirical approach. Eur J Finance 12(5):421-448

Gulati R, Gargiulo M (1999) Where do interorganizational networks come from? Am J Sociol 104(5):1439_ 1493

Hermalin BE, Weisbach MS (2003) Boards of directors as an endogenously determined institution: a survey of the economic literature. Econ Policy Rev Federal Reserve Bank of New York 9:7-26

Herskovic B (2018) Networks in production: asset pricing implications. J Finance 73(4):1785-1818

Horton J, Millo Y, Serafeim G (2012) Resources or power? Implications of social networks on compensation and firm performance. J Bus Finance Account 39:399-426

Hunter DR (2007) Curved exponential family models for social networks. Soc Netw 29(2):216-230 
Jacomy M, Venturini T, Heymann S, Bastian M (2014) Forceatlas2, a continuous graph layout algorithm for handy network visualization designed for the Gephi software. Plos One 9(6)

Jensen MC, Meckling WH (1976) Theory of the firm: managerial behavior, agency costs and ownership. J Financ Econ 3:305-360

Kanamitsu J (2013) Corporate social capital effect on company performance: a social network approach to study corporate scandals (in Japanese). Kyoto Management Review

Kawakami A (2017) Diversified firms and productivity in Japan. Public Policy Rev 13(2):153-166

Kramarz F, Thesmar D (1992) Social networks in the boardroom. J Eur Econ Assoc 11(4):780-807

Krichene H, Fujiwara Y, Chakraborty A, Arata Y, Hiroyasu I, Terai M (2019) The emergence of properties of the Japanese production network: How do listed firms choose their partners? Soc Net 59:1-9

Lamb NH, Roundy P (2016) The "ties that bind" board interlocks research: a systematic review. Manage Res Rev 39(11):1516-1542

Lincoln JR, Gerlach ML (2004) Intervention and redistribution: How keiretsu networks shape corporate performance. In: Japan's network economy. Cambridge UP

Lincoln JR, Gerlach ML, Takahashi P (1992) A dyad analysis of intercorporate ties. Am Sociol Rev 57(5):561-585

Lincoln JR, Shimotani M (2001) Whither the keiretsu, Japan's business networks? How were they structured? What did they do? Why are they gone? IRLE Working Paper No. 188-09

Mariolis P, Jones M (1982) Centrality in corporate interlock networks: reliability and stability. Adm Sci Q 27(4):571-585

Mian R, Nagata K (2015) Foreign institutional ownership and the valuation effect of investment and payout decision. J Finance Econ 3(5):97-104

Milaković M, Alfarano S, Lux T (2010) The small core of the German corporate board network. Comput Math Org Theory 16(2):201-215

Miwa Y, Ramseyer JM (2005) Who appoints them, what do they do? Evidence on outside directors from Japan. J Econ Manage Strateg 14(2):299-337

Mizruchi S (1996) What do interlocks do? An analysis, critique, and assesment of research on interlocking directorates. Annu Rev Sociol 271-298

Nakano M, Nguyen P (2012) Board size and corporate risk taking: further evidence from Japan. Corp Gov Int Rev 20(4):369-387

Petra ST (2005) Do outside independent directors strengthen corporate boards? Corp Gov Int J Bus Soc 5(1):55-64

Pfeffer J, Salancik GR (2003) The external control of organizations: a resource dependence perspective. Stanford University Press, Stanford

Raddant M, Milakovic M, Birg L (2017) Persistence in corporate networks. Econ Interact Coord 12(2):249_ 276

Schaede U (1995) The "old boy" network and government-business relationships in Japan. J Jpn Stud 21(2):293-317

Schommer M, Richter A, Karna A (2019) Does the diversification-firm performance relationship change over time? A meta-analytical review. J Manage Stud 56(1):270-298

Skinner DJ, Srinivasam S (2012) Audit quality and auditor repuation: evidence from Japan. Account Rev 87(5):1737-1765

Stearns LB, Mizruchi MS (1986) Broken-Tie reconstitution and the functions of interorganozational interlocks: a reexamination. Adm Sci Q 31(4):522-538

Strauss D, Ikeda M (1990) Pseudolikelihood estimation for social networks. J Am Stat Assoc 95:204-212

Sullivan BN, Tang Y (2013) Which signal to rely on? The impact of the quality of board interlocks and inventive capabilities on research and development alliance formation under uncertainty. Strateg Org 11(4):364-388

Uzzi B (1996) The sources and consequences of embeddedness for the economic performance of organizations: the network effect. Am Sociol Rev 61(4):674-698

Westphal JD, Boivie S, Chng DHM (2006) The strategic imptetus for social network ties: reconstitutiong broken CEO friendship ties. Strateg Manag J 27:425-445

Zona F, Gomez-Mejia LR, Withers MC (2018) Board interlocks and firm performance: towards a combined agency-resource dependence perspective. J Manag 44(2):586-618

Publisher's Note Springer Nature remains neutral with regard to jurisdictional claims in published maps and institutional affiliations. 